\title{
Do Citizens Reward European Union Funding? Evidence from Three Local Studies
}

\author{
Roman Senninger ${ }^{\dagger}$
}

\begin{abstract}
The European Union redistributes ever larger shares of its budget to enhance the economic performance of specific areas within its jurisdiction. However, there is little evidence of one of the most fundamental questions arising from this effort: Do citizens reward the European Union for funding that benefits their local environment? To answer this question, I leverage quasi-experimental data from an initiative that distributed vouchers to European municipalities to establish free and high-quality Wi-Fi connectivity before the European Parliament election in 2019. Moreover, I analyze geolocated data on beneficiaries of two major European Union funds, European Parliament election results along with register data from polling stations, and a citywide survey experiment in Denmark. The results show that European place-based funding has little to no impact on turnout and Eurosceptic voting in European Parliament elections. The findings are discussed in light of the recently introduced European Union recovery fund to combat economic downturn caused by the COVID-19 pandemic.
\end{abstract}

Word count: 10,300

\footnotetext{
†Department of Political Science, Aarhus University. Contact: rsenninger@ps.au.dk. I thank Anna Nguyen for excellent research assistance. I am grateful to David Andersen, Eri Bertsou, Daniel Bischof, Jonathan Doucette, Daniel Finke, Christoffer Green-Pedersen, Nicholas Haas, Madeleine Hosli, Matilde Jeppesen, Anne Mette Kjær, Lasse Leipziger, Jacob Nyrup, Tobias Risse, Julian Schuessler, Julia SchulteCloos, Henrik Seeberg, Svend-Erik Skaaning, Asbjørn Skjæveland, Gert Svendsen, Resul Umit, Vicente Valentim, and Tobias Varneskov for helpful comments. Previous versions of this paper were presented at MPSA 2021 and Aarhus University. I acknowledge financial support from the Aarhus University Research Foundation.
} 
"The EU budget has always comprised grants. (...) Grants for targeted investment and reforms, for more cohesion and for convergence of living standards in Europe. And our European Union is living proof that it works. This Union that has increased prosperity and living standards in every Member State. Investments made through the EU budget have paid off for all - many times over!"

- Ursula von der Leyen, President of the European Commission Brussels, 27 May 2020

\section{Introduction}

Do citizens reward the European Union for funding? This question is central to understanding public support for European integration and has been extensively debated (Anderson and Reichert, 1995; Gabel, 1998; Hobolt and De Vries, 2016). Today, the question is more topical than ever. The European Union is increasingly portrayed as a political system characterized by regional economic inequality and rising public discontent apparent by electoral support for Eurosceptic parties in European elections (Beckfield, 2019; De Vries, 2018; Rickard, 2020; Kriesi and Schulte-Cloos, 2020). To counteract these challenges, the European Union spends ever larger shares of its budget on place-based policy. As the term implies, the policy has a focus on specific localities and aims to enhance their economic performance (Neumark and Simpson, 2014). As part of the policy, the European Union finances hundreds of thousands of projects across its jurisdiction and European politicians frequently stress the positive effects of these local projects in an effort to become rewarded in European elections. To date, however, we do not have a full grasp of the success of this effort. There is surprisingly little evidence of politically relevant consequences arising from the European Union's place-based policy. In particular, it is unclear to what extent the policy helps to counteract discontent among voters at the local level where the policy is implemented.

The idea that European funding affects the attitudes and voting behavior of European citizens is derived from the utilitarian approach to understand public support for Euro- 
pean integration (Hobolt and De Vries, 2016). It is expected that citizens living in areas that benefit from funding will be more positive toward European integration. Several studies examine the possible relationship between European funding and citizen attitudes and behavior (Anderson and Reichert, 1995; Carrubba, 1997; Gabel, 1998; Hooghe and Marks, 2005; Chalmers and Dellmuth, 2015; Schraff, 2019; Dellmuth and Chalmers, 2018; Dijkstra, Poelman and Rodriguez-Pose, 2020; Schuessler, 2019; Borin, Macchi and Mancini, 2020). What is noticeable about much of this research is that it relies on highly aggregated data sources at the national and regional levels, which makes it difficult to examine the effects of place-based policies. European funding is ultimately allocated to private and public entities (e.g., municipalities, companies, universities) that realize projects locally, and there is plenty of evidence that exposure to cues and everyday occurrences in the local context greatly contributes to the formation of attitudes and subsequent voting behavior (Baybeck and McClurg, 2005; Newman et al., 2015; De BenedictisKessner and Warshaw, 2020; Bolet, 2021).

Based on this line of research, a proper understanding of the relationship between place-based policy and citizen attitudes and behavior requires a study of the local levels at which the policy is implemented. However, providing sound empirical evidence of the effects of place-based policy on citizen attitudes and behavior is extremely demanding, requiring data at very fine levels of geographic resolution and rigorous research designs employing plausible identification strategies. The main contribution of this paper is to present such valuable empirical evidence based on three studies at the local level. The three studies cover different initiatives of the European place-based policy as well as different European countries but focus on the same important outcome variables. To proxy whether citizens reward the European Union for place-based policy, I consider turnout and Eurosceptic voting in European Parliament elections. If European citizens directly reward the European Union for placed-based policy, one would expect higher levels of engagement with the European Union (i.e., higher turnout) and lower levels of support 
for Eurosceptic political parties.

The first study estimates the effect of European Union funding on turnout and voting in European Parliament elections at the municipality level in Austria, France, and Italy by exploiting an ideal regression discontinuity design. Fixed quotas of vouchers to establish free and high-quality Wi-Fi connectivity were made available for municipalities before the European Parliament election in 2019. Applications were submitted electronically and processed on a first come, first served basis until the available quotas were exhausted. Matching data on applications with voting records, I find no evidence that European funding increases turnout and decreases support for Eurosceptic parties.

The second study combines geolocated data on projects financed by two major European funds that were allocated between the European Parliament elections in 2009 and 2014 and voting results along with register data from polling stations in Denmark. Based on a difference-in-difference design, I do not find evidence for increased turnout, but polling station areas with a project funded by the European Union show lower levels of support for the main Eurosceptic party with a point estimate of -1.4 percentage points (95\% CI: -2.5 and -0.3$)$.

The third study uses survey experimental data collected in Denmark shortly before the European Parliament election in 2019. Results suggest that citizens of the country's second-largest city who were randomly exposed to information about projects funded by the European Union and realized in the city did not substantially differ in their intention to vote or support for the main Eurosceptic party compared to citizens who were exposed to similar information about European funding at the regional and national levels, and a control group receiving no information about European funding, respectively.

In sum, my results based on observational and experimental data provide little to no evidence that citizens reward the European Union for place-based funding that benefits their local environment. Even though the Eurosceptic vote share in Danish polling station areas decreases slightly as a response to place-based funding, it is very unlikely that 
effect sizes as the ones estimated would change overall election results to a considerable extent.

What could the European Union do to increase the likelihood of positive reactions to place-based funding in the future? In the final section of this paper, I discuss this question in light of my findings and the recently introduced recovery plan for Europe, which will distribute $€ 672.5$ billion in funds to help European Union member states address the economic and social impact of the COVID-19 pandemic. In particular, I suggest new forms of citizen involvement that are likely to increase citizens' stakes in funding decisions and that might help place-based funding feature more prominently in citizens' evaluations of the European Union. First, I briefly describe European Union place-based funding. Next, I discuss the related literature and point to the importance of considering the local level in empirical research. Thereafter, the research designs, data, analyses, and results of the three studies are presented. In addition to the discussion about the implications of my findings for the future of European funding, the paper closes with suggestions for future research.

\section{Place-Based Funding in the European Union}

Place-based funding in the European Union goes under the name of regional policy and is the Union's main re-distributive action aimed primarily at reducing the social and economic differences between European regions (Bache, 2015). Hundreds of thousands of projects are financed in the framework of the regional policy. Recent examples include the rehabilitation of the residential area Vila D'Este in the north of Portugal, the establishment of solar farms in Zielawa Valley in Poland's Lubelskie region, and a vocational school project laying the foundations for a more integrated Danish-German labor market in the Fehmarnbelt region.

Regional policy has a long history with multiple funds distributing ever-larger amounts. 
Originating in the early 1970's, the policy was substantially reformed in 1988, 1993, 1999, 2006, and 2013. Content and form of the policy changed several times as a result of negotiations between the European Commission and the Member States. Discussions between the involved parties usually concerned the definition of the policy's core objectives and their implementation (Blom-Hansen, 2005; Bachtler and Mendez, 2007). The lion share of today's regional policy is distributed through five funds that together make up the European structural and investment funds (ESIF). ${ }^{1}$ In the latest budget period from 2014 to 2020, the funds allocated more than $€ 400$ billion to projects across the European Union.

In addition, several initiatives outside the framework of the five ESIF funds similarly aim to enhance the economic performance of specific areas within the jurisdiction of the European Union. One of these initiatives is the so-called Connecting Europe Facility, a key European Union funding instrument that promotes growth, jobs, and competitiveness through targeted infrastructure investments in the fields of transport, energy, and digital services. Throughout the budget period from 2014 to 2020 more than $€ 30$ billion were invested in projects across the European Union. In sum, the European Union has steadily increased place-based funding with the aim of reducing inequality across geographic areas within its jurisdiction with the result that the regional policy accounts for the single largest chunk of the European Union budget.

\section{Considering the Local Level in Empirical Research}

Several studies examine the impact of European place-based funding on citizen attitudes and behavior. Earlier studies provide evidence for a positive association between

\footnotetext{
${ }^{1}$ These include the European Regional Development Fund, the European Social Fund, the Cohesion Fund, the European Agricultural Fund for Rural Development, and the European Maritime and Fisheries Fund. A brief description of the implementation and allocation processes of these funds is given in Section 4 of the Supplementary Materials.
} 
European redistribution and public support for the European Union (Carrubba, 1997; Hooghe and Marks, 2005). Two more recent studies find a positive association between European funding and citizen attitudes and behavior conditioned on the satisfaction of economic needs. Dellmuth and Chalmers (2018) show that European funding can increase European Union support when there is a good fit between spending areas and economic needs in the region. In a similar manner, Schraff (2019) shows that the likelihood of Eurosceptic voting is lower when European funding sufficiently compensates for economic decline.

Recent work also provides evidence based on causal identification strategies. Two studies that use eligibility thresholds for European Union funding in combination with regression discontinuity designs find opposing results. Borin, Macchi and Mancini (2020) estimate that increasing the per capita European transfers by $€ 100$ over the 2000-2014 period reduces the propensity to choose parties with a more negative stance towards $\mathrm{Eu}$ ropean integration by around 12 percentage points. Schuessler (2019) studies the period between 1989 and 2013 and finds estimates for the effect of European funding on public opinion to be relatively small and statistically insignificant. Another recent study estimates the effect of European Union funding on voting behavior using a spatial regression discontinuity design comparing East Wales and West Wales and shows that European Union money does not influence popular support for the European Union (Crescenzi, Cataldo and Giua, 2019).

What is noticeable about most of the studies presented above is that they focus on the Cohesion Fund within the ESIF and rely on highly aggregated data at the national and regional levels. However, European funding to the national and regional levels reflects an intermediate step in the allocation process because funds are ultimately allocated to private and public entities residing at fine levels of geographic resolution (e.g., municipalities, companies, universities, and private citizens). This final step in the allocation process is not considered in the existing literature. However, to understand the impact of 
European funding on citizen attitudes and behavior, one should aim to capture the process to its full extent. By examining the allocation to the national and regional levels only, we omit important information about the spatial distribution of European funds within countries and regions. As a result, we do not know whether funds are highly concentrated within regions benefiting only a few places or whether funds are equally distributed benefiting all locations to a similar extent.

Considering this kind of information is important because the distribution of funds and the precise location of funded projects at the local level can have an important impact on citizen attitudes and behavior. In fact, a large literature provides evidence that individuals consider cues and everyday occurrences in their local context when forming opinions about complex topics including the national economy (Reeves and Gimpel, 2012; Bisgaard, Dinesen and Sønderskov, 2016), climate change (Egan and Mullin, 2012; Bergquist and Warshaw, 2019), socio-cultural change (Bolet, 2021), immigration (Dinesen and Sønderskov, 2015; Hjorth, 2020), and terrorism (Agerberg and Sohlberg, 2021). ${ }^{2}$

The European Union constitutes a complex political topic as well. The European Union in general and European funding in particular are usually not at the forefront of people's minds. European funding is not prominently discussed in the political debate and does not feature in the media. Despite the increase in size, European place-based funding is hardly observable in the political debate, and average citizens are likely to experience the issue as being unobtrusive. If at all, citizens observe European funding in their local environment in which projects that are financed by the European Union are finally realized. To understand possible effects of European place-based funding, it is therefore important to investigate the phenomenon at fine levels of geographic resolution. In the following, I provide evidence from three empirical studies that shed light on several instruments of European place-based funding realized in different contexts. The

\footnotetext{
${ }^{2}$ Local context is a multifaceted phenomenon that can be defined and measured in different ways (Wong et al., 2012; Moore and Reeves, 2020; Baybeck and McClurg, 2005).
} 
studies have in common that they focus on the same important outcome variables and employ plausible identification strategies. For each study, I first describe the data and research design. Thereafter, I present the results of the analyses.

\section{Study 1: Data and Research Design}

The first study uses data from the WiFi4EU initiative, which is part of the above-described Connecting Europe Facility. The WiFi4EU initiative promotes free access to Wi-Fi connectivity for citizens in public spaces including parks, squares, public buildings, libraries, health centers and museums in municipalities throughout Europe. Municipalities are provided with the opportunity to apply for vouchers to the value of $€ 15,000$. Municipalities are selected on a first-come, first-served basis depending on the date and time of the submission of their application. The opportunity to apply opens on a pre-defined day and time. I focus on the first two rounds of the WiFi4EU initiative, which were completed before the European Parliament election in 2019. The first round was conducted on 7 November 2018 and the second round on 4 April 2019.

At the beginning of the application process, each Member State submits a list of municipalities eligible to apply for the vouchers. Each municipality can only benefit from one voucher during the entire duration of the WiFi4EU initiative. Therefore, municipalities awarded a voucher in a previous WiFi4EU call were not eligible to apply for a later call. On average, each Member State submitted a list consisting of 439 (1st call) and 334 (2nd call) municipalities, respectively. The number of registered municipalities roughly represents population figures. In both rounds, Italy registered most municipalities (i.e., 3,202 in the first round and 2,446 in the second round). Each participating Member State is guaranteed a minimum of 15 vouchers (provided they had sufficient applicants) capped to a number of vouchers corresponding to $8 \%$ of the budget, which was $€ 42$ million in the first round and $€ 51$ million in the second round. The results of the WiFi4EU ini- 
tiative were disseminated by successful municipalities and occasionally reported in the media (examples from Austria and Spain are shown in Figure SI 2). For both rounds, the results of the application process were published before the European Parliament election that took place on 23-26 May 2019. This provides an ideal opportunity to investigate whether European place-based funding has an impact on voting behavior in European Parliament elections.

How competitive was the application process in practice? Starting at 13:00 pm on application days, municipalities could $\log$ in to the WiFi4EU website and apply for vouchers. Applications were then processed on a first-come, first-served basis according to the order in which they were received by the electronic system. When the number of successful applications fills the quota established for a given country, no further municipalities can win a voucher. This mechanism generates a discontinuity in the probability of obtaining funding between those who applied in the seconds just before and the seconds just after the moment in which the quota is exhausted. The right-hand panel of Figure 1 shows how the probability of winning a voucher drops at the cutoff in France. The ratio of successful applications submitted before the quota is exhausted is very high as only very few applications were rejected, and it decreases to zero when the entire quota is exhausted (indicated by the value 0 on the $x$-axis). Depending on the country, this occurred within 2-75 seconds after the opening of the application system. All applications sent after the cutoff time were rejected. The left-hand panel of Figure 1 displays the number of applications over time. Immediately after $13: 00 \mathrm{pm}$, the system receives hundreds of applications, and after a few minutes, the flow has already decreased to nearly zero. It is evident from this pattern that municipalities were well aware of the 'first-come, firstserved' rule although the system was adopted for the first time in November 2018. 

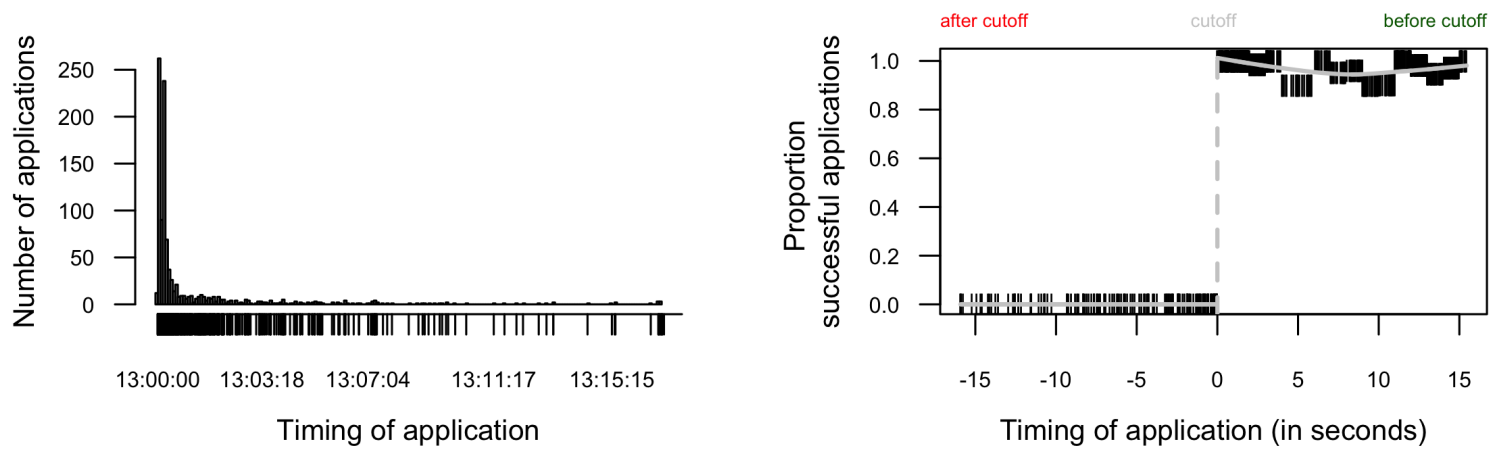

Figure 1: Number and Timing of Applications and Proportion of Successful Applications in France

Note: The x-axis in the right panel indicates the timing of the application relative to the cutoff in seconds. Positive values (i.e., to the right from the cutoff) indicate observations before the quota was exhausted and negative values (i.e., to the left of the cutoff) indicate observations after the quota was exhausted.

I created a dataset based on application documents available on the WiFi4EU platform. The data includes the country, municipality, the application time, the cutoff time, a variable whether the municipality submitted before or after the cutoff, and the treatment indicator (i.e., whether the municipality eventually obtained a voucher). ${ }^{3}$ The data on applications is matched with voting results from the European Parliament elections in 2014 and 2019 at the municipality level. The current analysis focuses on Austria, France, and Italy. The countries are mainly chosen for reasons of data availability. However, the countries represent important Member States due to their size, level of economic inequality, and prevalence of Eurosceptic party success.

The two outcome variables used in the empirical analysis are the difference in the vote share of the main Eurosceptic party (i.e., FPÖ in Austria, Front National in France,

\footnotetext{
${ }^{3}$ If a municipality did not receive funding in the first round and reapplied in the second round, only the second application outcome is matched with European Parliament election results. However, using firsttime applicants only and thus removing municipalities that applied more than once from the data does not alter the results.
} 
and Lega Nord in Italy) between 2014 and 2019 and the difference in turnout rates between the elections in 2014 and 2019. Both outcome variables are generated by subtracting the pre-funding values in 2014 from the post-funding values in 2019, thereby creating a gain score. The difference to 2014 is considered to increase the precision in my estimates. The number of observations is 552 for Austria of which 224 municipalities received a voucher 1,736 for France of which 586 municipalities received a voucher; and 3,661 for Italy of which 711 municipalities received a voucher. Descriptive statistics are presented in Table SI 1.

The analysis compares outcomes of municipalities whose application was received just before and just after the cutoff by using two empirical strategies. The first strategy applies the instrumental variable framework (IV) that allows treating application timing like a randomized encouragement design experiment where those who submitted just before the cutoff are encouraged to receive funding, while those who submitted just after the cutoff are encouraged not to receive funding. As described above, compliance is not perfect as some municipalities that submitted just before the cutoff fail to receive funding. To identify the local average treatment effect (LATE) of European funding for the subgroup of compliers, I compute the intention-to-treat effect, which is the effect of submitting just before the cutoff on the outcome variable, and divide it by the proportion of compliers in the sample, which is given by the first stage effect of submitting just before the cutoff on the probability of receiving funding.

To estimate the LATE, I code a binary treatment variable that captures whether the municipality received funding or not and a binary instrument variable that captures whether the municipality applied before the cutoff time or not. Next, I run a two-stage least squares model regressing the outcome on the treatment variable which I instrument with the instrumental variable. Importantly, this strategy relies on the fact that there are enough compliers in the sample, and, therefore, the first stage effect is sufficiently strong. As already shown in Figure 1, the probability of funding decreases sharply at the cutoff. In 
addition, I conduct tests showing that the instrument is indeed sufficiently strong. The IV strategy is applied on two different versions of the data. The first version uses all municipalities that participated in the lottery, and the second version is restricted to the most competitive municipalities that submitted within 5 minutes after the opening of the application system. Results for the three countries are estimated separately. Standard errors are clustered by administrative units at higher levels (i.e., state in Austria, department in France, and province in Italy).

I also apply a second, complementary, empirical strategy based on a fuzzy regression discontinuity $(\mathrm{RD})$ design that similarly removes selection into who receives funding. The fuzzy RD design exploits the exogenous variation generated among the subset of applicant municipalities who barely won or lost the lottery by just a few seconds. The running variable is the timing of each application relative to the cut-off (i.e., measured in seconds from the cutoff where positive values indicate observations before the quota was exhausted and negative values indicate observations after the quota was exhausted). In contrast to most RD designs in which treatment assignment depends on a pre-determined threshold rule, the cutoff in this case is unknown ex-ante and depends on the timing of submitted applications (including those from municipalities from other countries). This feature reinforces the fundamental identifying assumption that applications are as good as randomly assigned near the cutoff. An unambiguous identification of the cutoff is possible because the original application documents mark the last winning municipality per country (see Figure SI 1).

I use the continuity-based framework for the $\mathrm{RD}$ analysis and apply triangular kernel weights for RD estimation (Cattaneo, Idrobo and Titiunik, 2020). To determine the bandwidth, I apply the MSE approach, which optimizes the mean standard error. However, similar to the IV estimation I also present results based on manually selected bandwidths focusing on the most competitive municipalities that submitted within 5 minutes. To construct confidence intervals, I use the robust bias correction that leads to su- 
perior inference procedures compared to the conventional and standard bias correction (Calonico, Cattaneo and Titiunik, 2014). Since municipalities are clustered into higherlevel administrative units and errors might be correlated within these groups, I employ variance estimators that are robust to the clustered nature of the data.

\section{Study 1: Results}

Figure 2 shows the effect of WiFi4EU funding on differences in turnout and support for the main Eurosceptic parties in Austria, France, and Italy across different estimation strategies and model specifications. Point estimates are shown with cluster robust $95 \%$ confidence intervals.

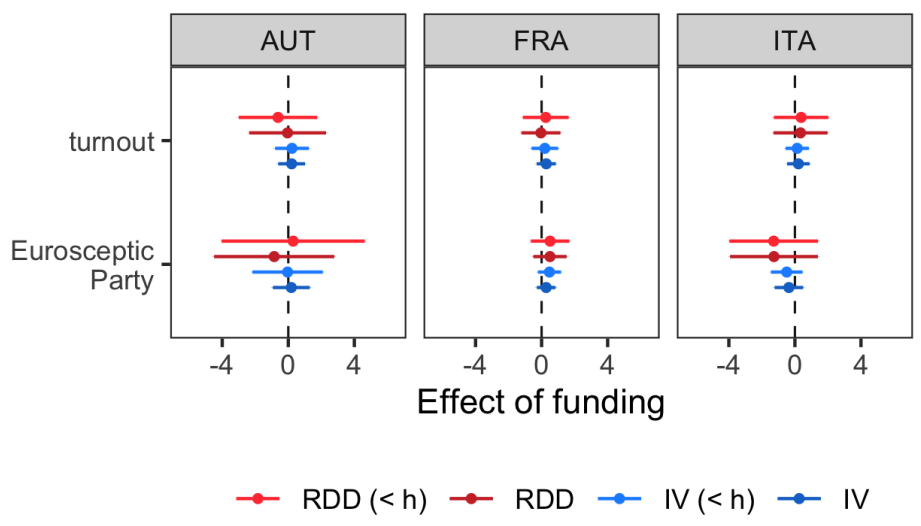

Figure 2: Estimates of Effect of European Funding on Turnout and Voting Behavior

Note: The model RDD shows results based on the MSE approch and RDD $(<\mathrm{h})$ shows results based on a manual bandwidth selection that includes the most competitive municipalities within five minutes. The IV model shows results based on the full data set, and IV $(<\mathrm{h})$ focuses on the most competitive municipalities within five minutes.

The light and dark red estimates refer to the fuzzy RD models based on MSE and manual bandwidth selection, respectively. The light and dark blue estimates refer to the IV models based on all municipalities and the most competitive municipalities, respectively. If voters reward the European Union for place-based funding, one should observe 
negative estimates in the case of the Eurosceptic party outcome and positive estimates regarding the turnout variable.

In general, the results provide no evidence that European funding leads to increases in turnout and decreases in support for Eurosceptic parties. I focus on the RD effect estimates first. In Italy, the point estimates regarding support for the main Eurosceptic party are negative (-1.27 and -1.29 percentage points) and positive for the turnout variable ( 0.34 and 0.38 percentage points). Even though the point estimates are rather small in size, these results would suggest that voters respond positively to funding that is distributed to their municipality. However, the confidence intervals around the point estimates are wide and include the value of zero.
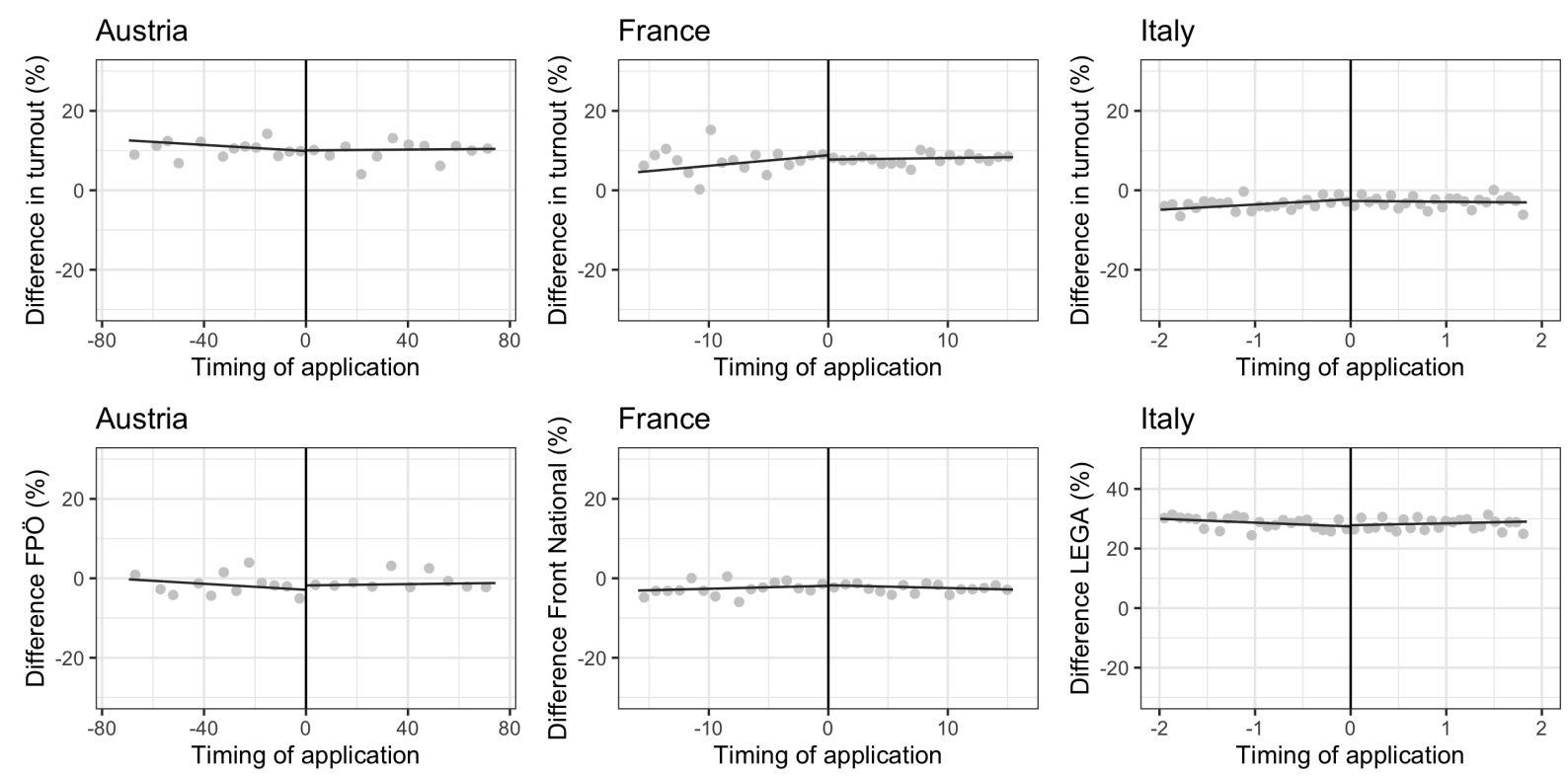

Figure 3: Mimicking Variance RD Plot with Evenly-Spaces Bins

Note:Upper panels use differences in turnout as dependent variable. Lower panels use differences in voting results for the main Eurosceptic party as dependent variable. The bandwidth covers the number of seconds (+/-) until the quota was exhausted. Positive values (+) indicate observations before the quota was exhausted, and negative values (-) indicate observations after the quota was exhausted. The global-polynomial of order 1 used to approximate the population conditional mean functions for control and treated units. The triangular kernel function is used to construct the local-polynomial estimator. Please note that the y-axis in the lower right-hand panel differs from the remaining panels.

The IV estimates point in the same direction. The point estimates are smaller and 
more precisely estimated. However, confidence intervals also include the value of zero. Taken together, this does not lend support that Italian voters reward the European Union in the European Parliament election in 2019 for place-based funding that has been allocated to their municipality.

In addition, the results based on data from Austria and France do not provide any evidence that voters respond positively to European funding. Point estimates are small and do not differ from zero. Some point estimates, for example the one for support for the main Eurosceptic party in France, even point in the opposite direction. The results based on the IV strategy are in line with the results from the RD approach, although again smaller and more precisely estimated. The uncertainty around the point estimates is largest for Austria, which is partly due to the smaller number of observations compared to Italy and France.

In addition to the above presented results, I provide regression discontinuity plots showing the data around the cutoff (i.e., indicating the timing of the application in seconds relative to the time when the quota was exhausted, which was after 75 seconds in Austria, 16 seconds in France, and 2 seconds in Italy). The figures provide a useful addition to the formal approach to estimation and inference above, and they suggest that there are no differences in turnout and voting results around the cutoff between municipalities that received European funding and those that did not. Additional RD plots using global-polynomials of higher order can be found in the Supplementary Materials (see Figure SI 3 and SI 4).

\section{Study 2: Data and Research Design}

The second study relies on fine-grained data about European funding in Denmark distributed between the European Parliament elections in 2009 and 2014. The data is provided by the Danish Business Authority, which administers projects funded by the 
European Union. The funded projects received funding from the European Regional Development Fund and the European Social Fund and cover a range of different purposes including the renovation of conference centers, the construction of tourist information points and workplaces for teleworkers, and the establishment of knowledge centers displaying new sustainable solutions. The projects have in common that they are locally implemented and thus relevant and visible for citizens in the immediate environment.

The main information used is the names and addresses of beneficiaries that received funding. In addition, for each funded project I can access the project title, the project's total budget, and the amount funded by the European Union. Denmark is one of the richest Member States and received a relatively small share of the $€ 347$ billion comprising the European Union's regional policy budget for the multi-annual budget period 2007-2013. In total, $€ 613$ million from the European Regional Development Fund and the European Social Fund were allocated to Denmark financing a total of 598 projects. In this study, I focus on the 321 projects initiated and realized in the period between the two European Parliament elections in June 2009 and May 2014. The data is analyzed using a two-period difference-in-difference research design.

To collect place-based information about European funding, I geocoded the addresses of beneficiaries of European Union funded projects. Geocoding is a computational process of assigning a location in the form of geographic coordinates (often expressed as latitude and longitude) to physical addresses. This creates information about European funding at the most disaggregated level, resulting in fine-resolution data points representing locations on the Earth's surface. A number of entries miss the address information. These are cases in which a municipality or region is listed as the beneficiary. To learn more about these projects, I searched for online information (e.g., project webpages, news reports) to find out who the beneficiary was and where the beneficiary was located. In most cases, it was possible to identify the location of the project. ${ }^{4}$

\footnotetext{
${ }^{4}$ For example, the project 'Øhavets Restaureringscenter' transforming an old shipyard into a cultural
} 
The geolocated data allows me to explore the spatial distribution within regions. Figure 1 shows the number of European Union-funded projects across the five regions (Panel A). It shows that numerous projects were realized in all of the five regions, but most projects were realized in the region North Jutland. However, the spatial distribution of realized projects (represented by black crosses) shown in Panel B of Figure 4 suggests that citizens living in the regions are differently exposed to European funding. As described above, such differences in exposure to European funding in the local context are likely to affect the formation of public opinion about European integration.
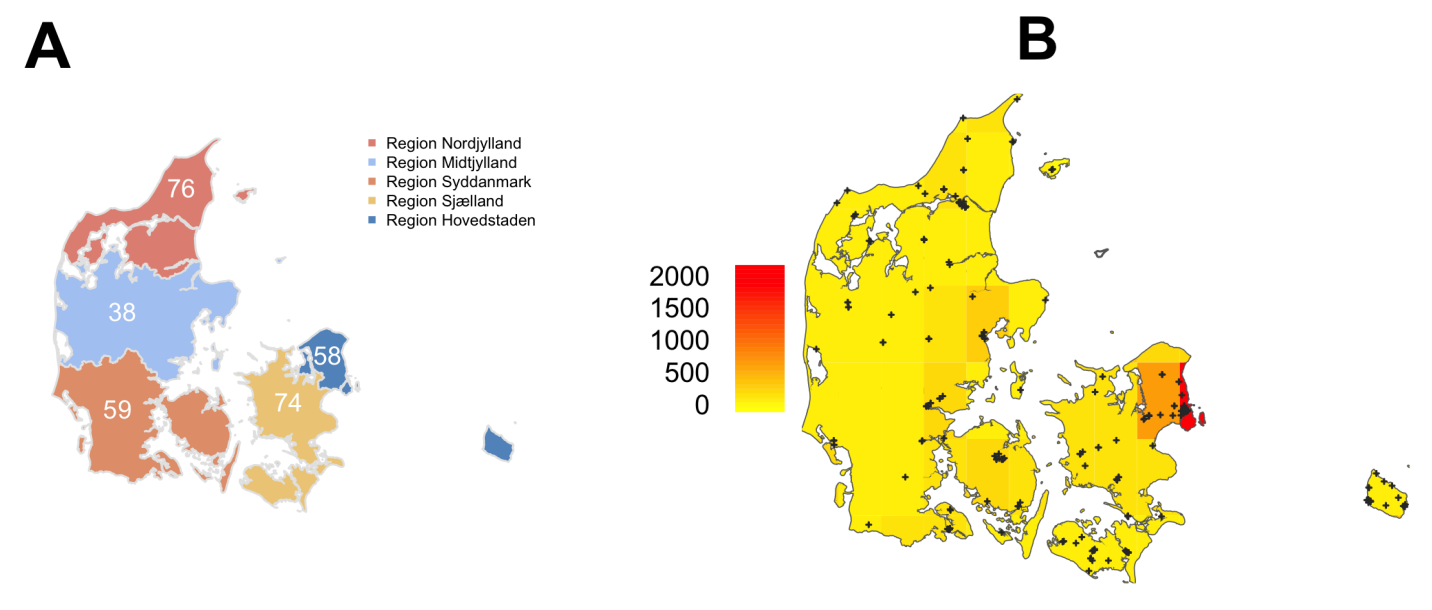

Figure 4: Funded Projects by region (Panel A) and Geo-Location of Realized Projects (Panel B)

Note: The black crosses in the right-hand panel represent realized European Union-funded projects between the EP elections in 2009 and 2014. The color-coding indicates population density estimates for the year 2005. The data is taken from Tollefsen, Strand and Buhaug (2012). Denmark is divided into 0.5 decimal degree grid cells (roughly $50 \times 50 \mathrm{~km}$ ). To obtain population density estimates, the number of people within each grid cell is divided by the total area covered by land (in square kilometers) in the grid cell.

and educational center listed Ærø Kommune as beneficiary. However, no address information was provided. An online search listed the project webpage with information about the location of the project. In sum, I was able to collect most of the missing data. A total of 16 out of 321 projects could not be clearly identified and thus missing in the data. 
In addition to the geolocated data on European funding, I use European Parliament election results from 2009 and 2014 and aggregated data from the Danish registers from the Danish voting database. The data is measured at the polling station level. The polling station level is the smallest administrative unit in Denmark and is mainly applied at elections and referendums.

In this study, the polling station area represents citizens' local context. ${ }^{5}$ The polling station area covers addresses within clearly defined geographic boundaries and assigns them to a polling location. Examples of polling stations along with their geographic coverage are provided in the Supplementary Materials (see Figure SI 5). For the European Parliament election in 2009 and 2014, Denmark was divided into nearly 1,400 polling station areas. The average size of polling station areas is $14.59 \mathrm{~km}^{2}$.

Similar to the first study, I use turnout rates and the vote share of the major Eurosceptic party (i.e., the Danish People's Party) as dependent variables. Turnout is used to examine whether European funding at the local level mobilizes citizens to engage with the European level. The vote share of the Danish People's Party approximates public support for European integration. To construct meaningful treatment variables measuring European funding, the geolocated data on European Union-funded projects described above was matched with the polling station level. More specifically, for each polling station area (polygon data), I identified how many of the geolocated projects (point data) fall within its boundaries. Information about the geographic boundaries of polling station areas was taken from the Danish Geodata Agency. I created three treatment variables for each polling station area. The first variable is a binary indicator reporting whether a project was realized in the polling station area or not. The second variable counts the total num-

\footnotetext{
${ }^{5}$ Measuring citizens' local context is a notoriously difficult task and the use of very small administrative units is just one out of many different operationalizations. In a recent study, Wong et al. (2020) show that most people consider "neighborhood", "places visited regularly", and "people and places seen weekly" when defining their local context. All these places and people are likely to be captured by the geographical boundaries of an individual's polling station area. Hence, while the polling station level is not the only possible operationalization of local context, it is certainly one of the most appropriate operationalizations.
} 
ber of projects realized within the polling station area. The third variable indicates the total amount of European Union funding (in million DKK) that was given to projects in the polling station area.

To estimate the effect of European funding on turnout and voting behavior, I use a two-period difference-in-difference design that compares the difference in post- and pre-funding outcomes between two groups: polling station areas that received funding (treatment group) and polling station areas that received no funding (control group). I estimate the following equation:

$$
\mathrm{y}_{i, t}=\alpha+\beta_{1} \text { treat }_{i}+\beta_{2} \text { post }_{t}+\beta_{3}\left(\text { treat }_{\mathrm{i}} \cdot \text { post }_{\mathrm{t}}\right)+\Gamma \mathrm{X}_{i t}+\zeta_{i}+\epsilon_{i, t}
$$

$\mathrm{y}_{i, t}$ is the outcome variable for polling station ${ }_{i}$ in period ${ }_{t}$ (EP election outcomes in 2009 represent the pre-funding period and 2014 the post-funding period). treat $_{i}$ is the group to which $i$ belongs (i.e., the treatment group or the control group). post $t_{t}$ is a dummy for the period, equal to 1 when $t=2014$ (i.e., post-funding) and 0 otherwise. $\left(\right.$ treat $_{\mathrm{i}} \cdot$ post $_{\mathrm{t}}$ ) indicates the interaction between the two terms, and the coefficient $\beta_{3}$ on the interaction term is an estimate of the treatment effect on the treated under the common trend assumption.

$\Gamma \mathrm{X}_{i t}$ represents time-varying socio-economic variables at the polling station level aggregated from the Danish administrative register. The following variables are included: the total number of households, the percentage of households with a gross income below 100,000 Danish crowns (roughly $€ 13,500$ ), the 80th percentile annual household income, and the percentage of non-Danish residents. Table SI 2 in the Supplementary Materials provides descriptive statistics. These variables allow me to control for possible differences in the socio-economic composition of polling station areas. To systematically control for polling station areas' common exposure to higher-level factors, models 
with municipality fixed effects $\left(\zeta_{i}\right)$ are specified. In sum, my estimation strategy exploits several advantages of the difference-in-difference research design including the possibility to use both binary and continuous treatment variables and the flexibility of adding additional covariates (Angrist and Pischke, 2008).

\section{Study 2: Results}

I begin by presenting the average treatment effect on the treated from models estimated using ordinary least squares with turnout (in \%) as the dependent variable. Table 1 shows three different model specifications for each of the three measurements of European funding. The first model specification only includes the corresponding measure of European funding. The second model specification adds municipality fixed effects. The third model specification adds the covariates presented above. Across the three different operationalizations of the treatment variable (funding yes/no, number of funded projects, and funding in million DKK) and the various model specifications, there is little evidence that European funding had an impact on turnout rates. Point estimates are close to zero, and the $95 \%$ confidence intervals of all estimates include the value of zero.

\begin{tabular}{lccc}
\hline \hline & \multicolumn{3}{c}{ Dependent variable: turnout (\%) } \\
\hline ATT (project yes/no) & 0.119 & 0.119 & 0.136 \\
95\% CI & {$[-1.682,1.920]$} & {$[-1.300,1.539]$} & {$[-1.037,1.310]$} \\
\hline ATT (no. of projects) & -0.059 & -0.059 & -0.063 \\
95\% CI & {$[-0.412,0.295]$} & {$[-0.337,0.219]$} & {$[-0.288,0.163]$} \\
\hline ATT (million DKK) & -0.007 & -0.007 & -0.007 \\
95\% CI & {$[-0.047,0.033]$} & {$[-0.039,0.024]$} & {$[-0.033,0.018]$} \\
\hline Municipality FE & & $\checkmark$ & $\checkmark$ \\
Covariates & & & $\checkmark$ \\
\hline
\end{tabular}

Table 1: Difference-in-Difference Estimates: Turnout

Note: For full regression tables, please see Table SI 3.

Table 2 shows results from models estimated using ordinary least squares with the vote share (in \%) of the Danish People's Party as the dependent variable. Model speci- 
fications follow the same pattern as discussed above. Across the three different operationalizations of European funding and the various model specifications, it shows that differences between the pre- and post-funding periods in the Eurosceptic vote share differ between polling station areas belonging to the treatment group and the control group. Treated polling station areas show less support for the major Eurosceptic party. While the point estimates for the treatment variables measuring the number of projects and total funding amount in million DKK are very small in size, the point estimates for the binary treatment variable (i.e., project yes/no) show an estimated average treatment effect on the treated of -1.4 (95\% CI: -2.5 and -0.3). However, to interpret the substantial size one has to take the local level of analysis into account. Even though a 1.4 percentage point decrease is a notable difference for the individual polling station area, it does not make a huge difference for the final election result.

\begin{tabular}{lccc}
\hline \hline & \multicolumn{3}{c}{ Dependent variable: DF (\%) } \\
\hline ATT (project yes/no) & -1.387 & -1.387 & -1.402 \\
95\% CI & {$[-2.920,0.147]$} & {$[-2.489,-0.284]$} & {$[-2.496,-0.308]$} \\
\hline ATT (no. of projects) & -0.301 & -0.301 & -0.298 \\
95\% CI & {$[-0.600,-0.003]$} & {$[-0.517,-0.086]$} & {$[-0.508,-0.087]$} \\
\hline ATT (million DKK) & -0.039 & -0.039 & -0.038 \\
95\% CI & {$[-0.072,-0.005]$} & {$[-0.063,-0.014]$} & {$[-0.062,-0.014]$} \\
\hline Municipality FE & & $\checkmark$ & $\checkmark$ \\
Covariates & & & $\checkmark$ \\
\hline
\end{tabular}

Table 2: Difference-in-Difference Estimates: Danish People's Party Note: For full regression tables, please see Table SI 4.

In addition to the main results presented above, I conduct several robustness tests. It might be that citizens not only consider European funding directly allocated to their polling station area but also observe and respond to European funding in the neighboring polling station areas. I therefore estimate models that take European funding allocated to neighboring polling station areas into account. The models add a spatial variable that is the product of a row-standardized connectivity matrix based on direct contiguity and the corresponding operationalization of European funding. The model results 
show that adding the variable accounting for European funding in neighboring polling stations does not substantially change the coefficients of the three European funding variables in the focal polling station area (see Table SI 6 and Table SI 7).

A few polling station areas received considerably more European funding both in terms of total amounts and realized projects than the average funded polling station area. I therefore re-estimate models using the share of the Danish People's Party as dependent variable by means of leave-on-out estimation. Hence, each model leaves one of the polling station areas out at a time. Results are presented in Figure SI 6 in the appendix which shows the distribution of point estimates as well as upper and lower confidence intervals by means of density plots. Across the 1362 models, point estimates and estimated 95\% confidence intervals are similar to the ones presented in Table 2.

\section{Study 3: Data and Research Design}

The third study is based on a survey experiment conducted online using the private polling agency YouGov. The target population was the voting-age population of Aarhus (i.e., Denmark's second largest city). The sample was collected using a dynamic sampling technique, where respondents from YouGov's online panel matching the key characteristic of the target population were continuously invited to participate in the survey. The sample is highly diverse in terms of age, gender, education, and occupation. The total number of respondents who participated in the study is 578. The fielding period was in the week of the European Parliament election 2019. The data collection started on Wednesday 22 May and ended on Saturday 25 May 2019, the day before the election. The fielding period was deliberatively chosen because of the proximity to the European Parliament election, which allowed for the collection of relevant outcome measures similar to the outcomes in the above-presented studies.

To approximate turnout, respondents were asked: "Will you vote in the European Par- 
liament election on 26 May 2019?". Respondents were provided with seven options: “I'll definitely vote", “I'll probably vote”, “I'll probably not vote”, “I'll definitely not vote”, “I have already voted by mail”, "I don't have the right to vote”, and "don't know”. I removed the respondents that had already voted, that did not have the right to vote, or that answered "don't know". The variable is scaled from 0 to 1 , where 1 is most definitely voting $(\mathrm{M}=0.89, \mathrm{SD}=0.21)$. In addition, the question "Which party do you think you will vote for in the European elections on 26 May 2019?" was used to measure which party a respondent is likely to vote for. Similar to study 2 above, I focus on the Danish People's Party to measure Eurosceptic voting. I recoded the variable so that respondents who will vote for the Danish People's Party receive a value of 1 and 0 otherwise $(\mathrm{M}=0.07, \mathrm{SD}=0.26) .{ }^{6}$ The two questions constitute the key outcome variables and were asked after the experimental component of the survey.

The survey experiment was designed to resemble an opinion survey in which respondents were asked whether they have heard about certain topics throughout the election campaign. The topics refer to Denmark's role and activities in the European Union. The first two topics were identical for all respondents. After a brief introduction, respondents were asked whether they have heard or read something about the European Union Committee of the Danish Parliament and the work of the Danish European Union Commissioner during the election campaign. Both topics were briefly introduced before the questions were asked (see Section 3.1 in the Supplementary Materials). Respondents who answered "yes" were further asked where they have heard or read something about the topic. The two topics were chosen because they depict relatively neutral content about Denmark's membership and involvement in European Union politics.

Next, the sample was randomly split into four different groups (three treatment conditions and one control condition). ${ }^{7}$ Respondents in the three treatment conditions were

\footnotetext{
${ }^{6}$ The Danish People's Party's vote share at the European Parliament election 2019 in Aarhus was 6.2\%. Hence, the survey result (7\%) comes very close to the final election result.

${ }^{7}$ Randomization produced balance across a number of covariates (see Section 3.1 in the Supplementary
} 
asked about a third topic. This third topic represents the stimulus material that informs respondents about European funding at three different geographic levels (i.e., local, regional, and national). ${ }^{8}$ The wording of the stimulus material is as follows:

\section{Experimental manipulation}

"The European Union's regional policy aims to stimulate the economic growth of European regions and cities through investment.

Since 2007, [more than 60 /more than $120 /$ hundreds of] projects have been completed and a total amount of approx. [400 million/700 million/6.4 billion] DKK has been invested in innovation, education and employment in [Aarhus/Midtjylland/Denmark].

Did you hear or read anything about European Union investments in [Aarhus/Midtjylland/Denmark] during the European Parliament election campaign?"

Note: Bold text indicates the differences in the stimulus material across the three geographic levels.

The information about the number of projects and total amount of European funding allocated to the various levels is based on the list of European Union funded projects in the funding periods from 2007 to 2013 and from 2014 up to the week before the European Parliament election 2019 made available by the Danish Business Authority. In sum, the use of three treatment conditions representing different geographic levels and a control group allow for a comprehensive comparison between citizen responses to European funding at the local, regional, and national levels. First, one can test whether

Materials). However, gender is not balanced across conditions. I therefore present results accounting for gender in the Supplementary Materials (see Table SI 7). The results do not change when accounting for gender.

${ }^{8}$ There are several reasons why the level of the stimulus material in the third study operates at the city level and beyond. First, to avoid misinformation, I had to provide accurate stimulus material about European funding in the local context to all treated respondents. If I would operate at the polling station level or below, I would not be able to guarantee that the polling station area in which a respondent that is randomly assigned to the treatment condition lives has actually received European Union funding. Hence, to give respondents in the treatment group accurate information while at the same time making sure that they are actually treated with a positive cue on European funding, I rely on stimulus material at the city level and beyond. In addition, collecting data from areas smaller than the city level would lead to challenges because polling agencies were not able to target respondents in areas below the city level. Apart from reasons related to research design, the city level is of particular interest because urban areas are the places where a majority of European funding is allocated. For example, throughout the funding period from 2007 to 2013, $40 \%$ of the projects were realized in the four largest Danish cities (i.e., Copenhagen, Aarhus, Odense, and Aalborg). 
respondents in the treatment groups differ in their behavior and attitudes compared to the control group. If yes, this would indicate that citizens respond to cues about European funding. On the other hand, one can compare possible differences between the three treatment conditions. Here, it is particularly interesting whether citizens respond more strongly to information about European Union funding in their local context (i.e., city) as compared to information about European Union funding in a larger geographic contexts (i.e., region and country).

\section{Study 3: Results}

The overall results of the experiment are reported in Figure 5. First, for intention to vote in the European Parliament election in Panel A, the average intention is slightly larger for respondents in the local treatment condition $(\mathrm{M}=0.924, \mathrm{SD}=0.203, \mathrm{~N}=124)$ compared with the control group $(\mathrm{M}=0.8915, \mathrm{SD}=0.241, \mathrm{~N}=126)$ with a difference in means statistic of $\mathrm{t}(248)=1.18, \mathrm{p}=0.24$, difference $=0.03$. However, the design and test combination does not have sufficient power to detect an effect of this size at conventional levels of statistical significance. The differences between the two remaining treatment conditions (i.e., regional $(\mathrm{N}=124)$ and national $(\mathrm{N}=125))$ and the control group are even smaller. For the regional treatment group the results are $t(248)=-0.06, p=0.95$, difference $=-0.00$ and for the national treatment group $\mathrm{t}(249)=0.45, \mathrm{p}=0.65$, difference $=0.01$. The results suggest that a high proportion of respondents in the study are located at the upper limit regarding the reported intention to vote. This makes discrimination among respondents very difficult. Panel B shows results in which the treatment conditions are collapsed. The average intention is slightly larger for respondents in the treatment conditions $(\mathrm{M}=0.906, \mathrm{SD}=0.201, \mathrm{~N}=373)$ compared with the control group $(\mathrm{M}=0.892, \mathrm{SD}=0.242, \mathrm{~N}=126)$ with a difference in means statistic of $\mathrm{t}(497)=0.67, \mathrm{p}$ $=0.50$, difference $=0.014$. Accounting for whether respondents report to have heard or 
read anything about European Union investments does not alter the results.

As regards the reported intention to vote for the major Eurosceptic party, it shows that the average vote share for the Danish People's Party is consistently lower in the three treatment conditions compared to the control group (see Panel C in Figure 5). The vote share of the Danish People's Party across the three treatment groups is 2-3 percentage points lower compared to the control group.
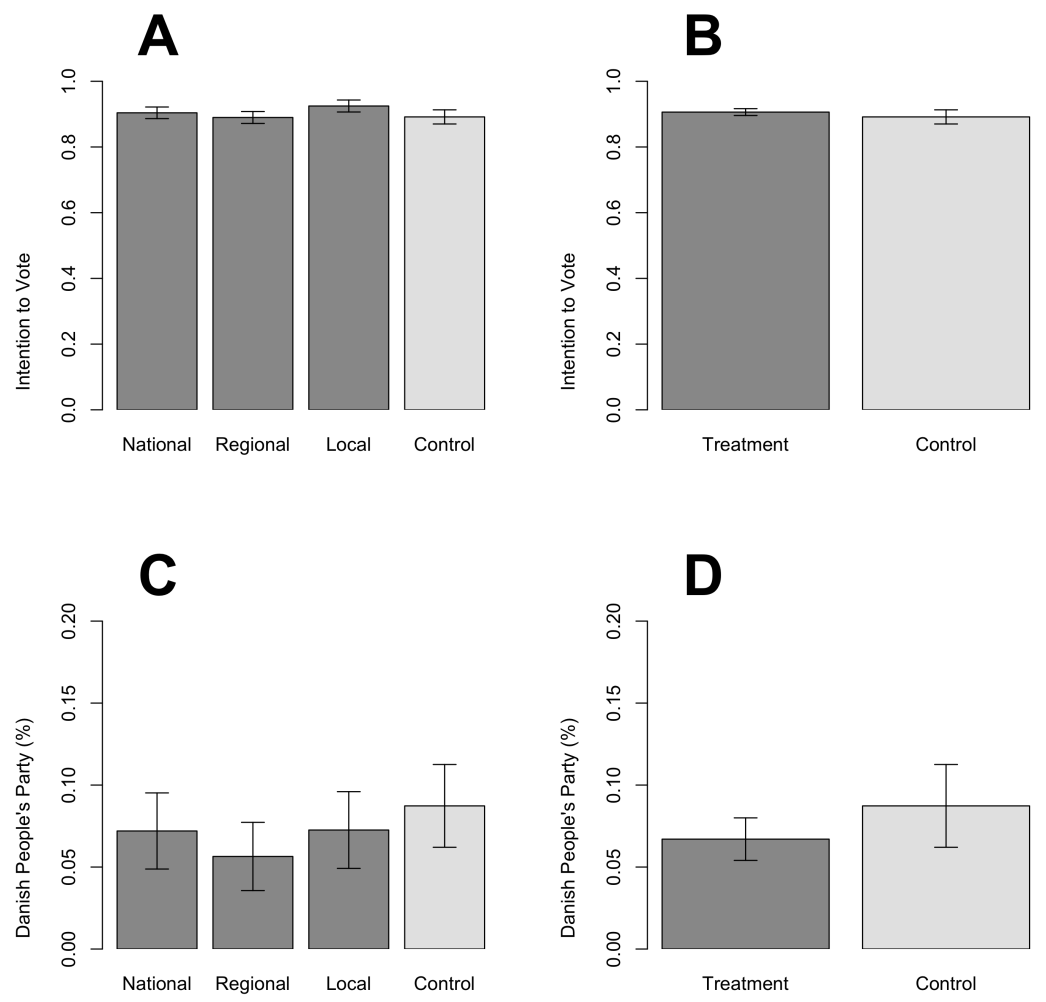

Figure 5: Mean Values and Error Bars across Treatment Conditions

Note: Turnout (Panel A and B) and Danish People's Party (Panel C and D). Error bars indicate 95\%-confidence intervals.

This finding is in line with the results from study 2 that show slightly lower levels of support for the Danish People's Party in polling station areas that benefited from European Union funding. However, the design and test combination does not have sufficient 
power to detect an effect of this size at conventional levels of statistical significance. ${ }^{9}$

The difference in means statistics are $t(248)=-0.43, p=0.67$, difference $=-0.02$ for the local treatment group, $\mathrm{t}(248)=-0.94, \mathrm{p}=0.35$, difference $=-0.03$ for the regional treatment group, and $\mathrm{t}(249)=-0.45, \mathrm{p}=0.66$, difference $=-0.02$ for the national treatment group Taken together, there is little evidence for substantial differences between respondents exposed to European funding at three geographic levels (local, regional, and national) and respondents in the control group. Panel D shows results in which the treatment conditions are collapsed. The average intention to vote for the Danish People's Party is visibly lower for respondents in the treatment conditions $(\mathrm{M}=0.067, \mathrm{SD}=0.250, \mathrm{~N}=373)$ compared with the control group $(\mathrm{M}=0.087, \mathrm{SD}=0.283, \mathrm{~N}=126)$ with a difference in means statistic of $\mathrm{t}(497)=-0.75, \mathrm{p}=0.45$, difference $=-0.02$. Again, whether respondents report to have heard or read anything about European Union funding does not change my conclusion.

\section{Conclusion and Discussion}

The European Union redistributes ever larger shares of its budget to enhance the economic performance of specific areas within its jurisdiction. In this paper, I provide new empirical evidence on an important question: Do citizens reward the European Union for funding that benefits their local environment? My focus is on the European Union for two interdependent reasons. On the one hand, it is a political system characterized by regional economic inequality and rising public discontent. On the other hand, it implements one of the largest place-based policies in the world. Contrary to previous research that examines possible attitudinal and behavioral consequences of place-based European funding at highly aggregated levels of analysis, I examine citizen responses at

\footnotetext{
${ }^{9}$ The design has good sensitivity to larger effects (e.g., the size of effect as reported in Borin, Macchi and Mancini (2020).
} 
very fine levels of geographic resolution.

In sum, my results based on observational and experimental data provide little to no evidence that citizens reward the European Union for place-based funding. Citizens living in areas that benefit from European place-based funding do not participate in European Parliament elections at higher rates or support Eurosceptic parties at considerably lower rates. Only in one study based on geolocated data from Denmark do I find that citizens respond to place-based funding with a little less support for the major Eurosceptic party. The funded projects considered in this study are part of the ESIF funds and come with vastly larger benefits (on average $€ 930,000$ ) than the Wi-Fi vouchers worth $€ 15,000$ considered in the first study. This suggests that the size of funding in the local area - and thus the strength of the treatment - might matter for citizen responses to European placed-based funding. However, the effect size is still relatively small and the estimated responses to place-based funding do not change the election result in a substantial manner. In sum, my findings suggest that even though funded projects are realized in citizens' immediate environment, they do not seem to impact considerably on citizens' voting behavior.

How could this be changed in the future? The European Union is about to implement a massive recovery package that will make $€ 672.5$ billion in loans and grants available to support reforms and investments. The aim of the recovery package is to mitigate the economic and social impact of the coronavirus pandemic and make European economies and societies more sustainable, resilient, and better prepared for the challenges and opportunities of the green and digital transitions. As part of the recovery package, the European Union will finance hundreds of thousands of projects across its regions. If the European Union aspires to win the hearts of European citizens with recovery funding, it might be time to reconsider the role of citizens in the realization of local projects.

A possible reason why citizens respond little to European funding in their local environment could be the lack of interaction with realized projects. Recent research suggests 
that citizens respond to events in their immediate environment if they meaningfully engage with these events (Larsen et al., 2019). Even though citizens observe and notice projects funded by the European Union in their local environment, they seem to hardly engage with the projects. A possible result of this lack of active engagement is that positive views about European funding in the local environment do not feature prominently in evaluations of the European Union. To change this, European citizens could become involved in the project selection or contribute to the planning and implementation of local projects. This would lead to the case that citizens have a stake in the projects that are realized in their local context. Using randomized evaluations to study the effects of such citizen interaction with European funding, one would gain new and important knowledge about the attitudinal and behavioral consequences of European funding.

In addition, future research should study local exposure to European funding more systematically. This paper has called attention to the importance of examining the consequences of European funding at the local level. Using different kinds of local data, including georeferenced information about funded projects, I have shown how possible responses to European funding can be studied by operating at fine levels of geographic resolution. My approach can be used as a stepping stone for future research with the aim of studying the consequences of European funding at the local level. Building on recent developments in the measurement of local context, one particularly interesting approach would be to study local exposure to European funding using dynamic data that tracks individuals' proximity to funded projects over a longer period of time (Moore and Reeves, 2020; Hamel and Wilcox-Archuleta, N.d.). 


\section{References}

Agerberg, Mattias and Jacob Sohlberg. 2021. "Personal Proximity and Reactions to Terrorism." Comparative Political Studies pp. 1-34.

Anderson, Christopher J. and M. Shawn Reichert. 1995. "Economic Benefits and Support for Membership in the E.U.: A Cross-National Analysis." Journal of Public Policy 15(3):231-249.

Angrist, Joshua D. and Jörn-Steffen Pischke. 2008. Mostly Harmless Econometrics: An Empiricist's Companion. Princeton University Press.

Bache, Ian. 2015. Cohesion Policy - A New Direction for New Times? In Policy-Making in the European Union, ed. Hellen Wallace, Mark A. Pollack and Alasdair R. Young. Oxford University Press pp. 243-262.

Bachtler, John and Carlos Mendez. 2007. "Who Governs EU Cohesion Policy? Deconstructing the Reforms of the Structural Funds." JCMS: Journal of Common Market Studies 45(3):535-564.

Baybeck, Brady and Scott D. McClurg. 2005. "What Do They Know and How Do They Know It?: An Examination of Citizen Awareness of Context." American Politics Research 33(4):492-520.

Beckfield, Jason. 2019. Unequal Europe - Regional Integration and the Rise of European Inequality. Oxford: Oxford University Press.

Bergquist, Parrish and Christopher Warshaw. 2019. "Does Global Warming Increase Public Concern about Climate Change?” The Journal of Politics 81(2):686-691.

Bisgaard, Martin, Peter Thisted Dinesen and Kim Mannemar Sønderskov. 2016. "Reconsidering the Neighborhood Effect: Does Exposure to Residential Unemployment Influence Voters' Perceptions of the National Economy?" The Journal of Politics 78(3):719732.

Blom-Hansen, Jens. 2005. "Principals, agents, and the implementation of EU cohesion policy.” Journal of European Public Policy 12(4):624-648.

Bolet, Diane. 2021. "Drinking Alone: Local Socio-Cultural Degradation and Radical Right Support-The Case of British Pub Closures.” Comparative Political Studies pp. 1-40.

Borin, Alessandro, Elisa Macchi and Michele Mancini. 2020. "EU transfers and Euroscepticism: can't buy me love?" Economic Policy pp. 1-30.

Calonico, Sebastian, Matias D. Cattaneo and Rocio Titiunik. 2014. "Robust Nonparametric Confidence Intervals for Regression-Discontinuity Designs.” Econometrica 82(6):2295-2326. 
Carrubba, Clifford J. 1997. "Net Financial Transfers in the European Union: Who Gets What and Why?" The Journal of Politics 59(2):469-496.

Cattaneo, Matias D., Nicolás Idrobo and Rocío Titiunik. 2020. A Practical Introduction to Regression Discontinuity Designs: Foundations. Cambridge University Press.

Chalmers, Adam William and Lisa Maria Dellmuth. 2015. "Fiscal redistribution and public support for European integration.” European Union Politics 16(3):386-407.

Crescenzi, Riccardo, Marco Di Cataldo and Mara Giua. 2019. "It's not about the money! EU funds, local opportunities, and the Brexit vote." LSE 'Europe in Question' Discussion Paper Series Paper No. 149/2019:1-21.

De Benedictis-Kessner, Justin and Christopher Warshaw. 2020. "Accountability for the Local Economy at All Levels of Government in United States Elections." American Political Science Review 114(3):660-676.

De Vries, Catherine. 2018. Euroscepticism and the Future of European Integration. Oxford University Press.

Dellmuth, Lisa M. and Adam W. Chalmers. 2018. "All spending is not equal: European Union public spending, policy feedback and citizens' support for the EU." European Journal of Political Research 57(1):3-23.

Dijkstra, Lewis, Hugo Poelman and Andres Rodriguez-Pose. 2020. Regional Studies 54(6):737-753.

Dinesen, Peter Thisted and Kim Mannemar Sønderskov. 2015. "Ethnic Diversity and Social Trust: Evidence from the Micro-Context." American Sociological Review 80(3):550573.

Egan, Patrick J. and Megan Mullin. 2012. "Turning Personal Experience into Political Attitudes: The Effect of Local Weather on Americans' Perceptions about Global Warming." The Journal of Politics 74(3):796-809.

Gabel, Matthew J. 1998. Interests and Integration: Market Liberalization, Public Opinion, and European Union. University of Michigan Press.

Hamel, Brian T. and Bryan Wilcox-Archuleta. N.d. "Black Workers in White Places: Daytime Racial Diversity and White Public Opinion.” The Journal of Politics pp. 1-10.

Hjorth, Frederik. 2020. “The Influence of Local Ethnic Diversity on Group-Centric Crime Attitudes." British Journal of Political Science 50(1):321-343.

Hobolt, Sarah B. and Catherine E. De Vries. 2016. "Public Support for European Integration." Annual Review of Political Science 19(1):413-432.

Hooghe, Liesbet and Gary Marks. 2005. "Calculation, Community and Cues: Public Opinion on European Integration.” European Union Politics 6(4):419-443. 
Kriesi, Hanspeter and Julia Schulte-Cloos. 2020. "Support for radical parties in Western Europe: Structural conflicts and political dynamics.” Electoral Studies 65:102138.

Larsen, Martin Vinæs, Frederik Hjorth, Peter Thisted Dinesen and Kim Mannemar Sønderskov. 2019. "When Do Citizens Respond Politically to the Local Economy? Evidence from Registry Data on Local Housing Markets." American Political Science Review 113(2):499-516.

Moore, Ryan T. and Andrew Reeves. 2020. "Defining Racial and Ethnic Context with Geolocation Data." Political Science Research and Methods 8(4):780-794.

Neumark, David and Helen Simpson. 2014. Place-Based Policies. Working Paper 20049 National Bureau of Economic Research.

URL: $h t t p: / / w w w . n b e r . o r g / p a p e r s / w 20049$

Newman, Benjamin J., Yamil Velez, Todd K. Hartman and Alexa Bankert. 2015. "Are Citizens Receiving the Treatment? Assessing a Key Link in Contextual Theories of Public Opinion and Political Behavior." Political Psychology36(1):123-131.

Reeves, Andrew and James G. Gimpel. 2012. "Ecologies of Unease: Geographic Context and National Economic Evaluations.” Political Behavior 34(3):507-534.

Rickard, Stephanie J. 2020. "Economic Geography, Politics, and Policy." Annual Review of Political Science 23(1):187-202.

Schraff, Dominik. 2019. "Regional redistribution and Eurosceptic voting." Journal of European Public Policy 26(1):83-105.

Schuessler, Julian. 2019. “Can the EU Buy Public Support?" SocArXiv, Working Paper, doi:10.31235/osf.io/ut8r9.

Tollefsen, Andreas Forø, Håvard Strand and Halvard Buhaug. 2012. "PRIO-GRID: A unified spatial data structure." Journal of Peace Research 49(2):363-374.

Wong, Cara, Jake Bowers, Daniel Rubenson, Mark Fredrickson and Ashlea Rundlett. 2020. "Maps in People's Heads: Assessing a New Measure of Context." Political Science Research and Methods 8(1):160-168.

Wong, Cara, Jake Bowers, Tarah Williams and Katherine Drake Simmons. 2012. "Bringing the Person Back In: Boundaries, Perceptions, and the Measurement of Racial Context." The Journal of Politics 74(4):1153-1170. 


\section{Appendix}

\section{Do Citizens Reward European Union Funding? Evidence from Three Local Studies}

\section{Contents}

1 Study $1 \quad 2$

1.1 Additional information about the application process . . . . . . . 2

1.2 Descriptive statistics . . . . . . . . . . . . . . 3

1.3 Additional results . . . . . . . . . . . . . . . 4

2 Study 2 6

2.1 Polling station areas . . . . . . . . . . . . . . 6

2.2 Descriptive statistics . . . . . . . . . . . . . 7

2.3 Accounting for European funding in neighboring polling stations . . . 10

2.4 Leave-one-out estimation . . . . . . . . . . . . . . . 10

3 Study $3 \quad 13$

3.1 Question wording of the two neutral topics . . . . . . . . . . . 13

3.2 (Most) Covariates are balanced across treatment conditions . . . . . . . 14

3.2.1 Results controlling for gender . . . . . . . . . . . . 15

4 The process of allocating European funds $\quad 16$ 


\section{Study 1}

\subsection{Additional information about the application process}

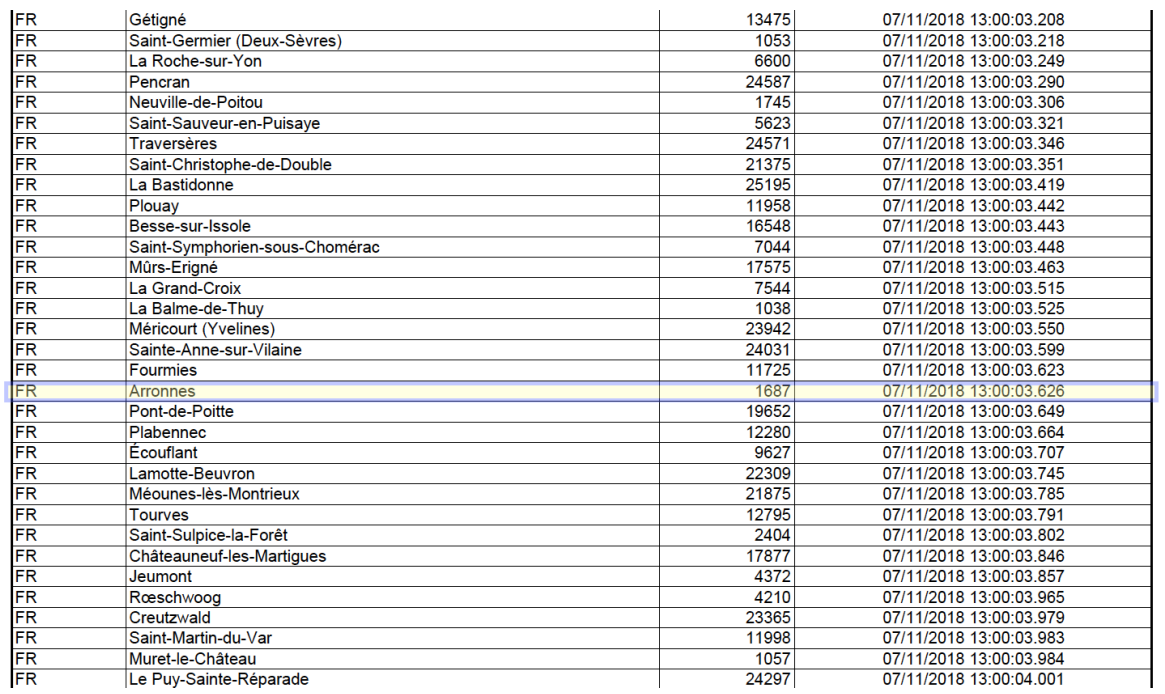

Figure SI 1: WiFi4EU 2018 Round 1 - List of applications (alphabetical order by Member State)

Note: The last winning municipality from France is highlighted.

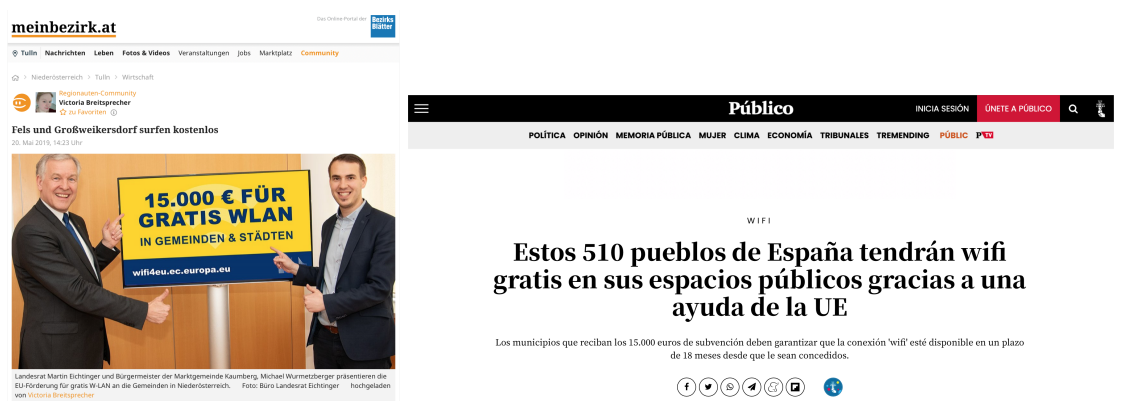

Figure SI 2: Media articles about WiFI4EU winners before the EP election 


\subsection{Descriptive statistics}

\begin{tabular}{|c|c|c|c|c|c|}
\hline Variable & $\mathrm{N}$ & Mean & St. Dev. & Min & Max \\
\hline \multicolumn{6}{|l|}{ Austria } \\
\hline Seconds from cutoff & 552 & -17126 & 34750.43 & -171703.54 & 74.32 \\
\hline Below cutoff & 552 & 0.42 & 0.49 & 0 & 1 \\
\hline Funding Received & 552 & 0.41 & 0.49 & 0 & 1 \\
\hline Turnout EP 14' & 552 & 43.44 & 9.36 & 13.57 & 67.88 \\
\hline Turnout EP 19' & 552 & 53.63 & 7.98 & 33.57 & 73.80 \\
\hline Difference Turnout & 552 & 10.18 & 3.96 & -2.47 & 23.88 \\
\hline Eurosceptic Party Support EP 14' & 552 & 20.39 & 5.86 & 3.67 & 39.50 \\
\hline Eurosceptic Party Support EP 19' & 552 & 18.49 & 5.26 & 2.74 & 41.46 \\
\hline Difference Eurosceptic Party Support & 552 & -1.89 & 3.86 & -27.29 & 16.68 \\
\hline Electorate & 552 & 3278 & 9106.36 & 140 & 197436 \\
\hline \multicolumn{6}{|l|}{ France } \\
\hline Seconds from cutoff & 1736 & -21346 & 44956.07 & -186694.24 & 15.45 \\
\hline Below cutoff & 1736 & 0.35 & 0.48 & 0 & 1 \\
\hline Funding Received & 1736 & 0.34 & 0.47 & 0 & 1 \\
\hline Turnout EP 14' & 1736 & 46.66 & 7.04 & 6.77 & 75.00 \\
\hline Turnout EP 19’ & 1736 & 54.52 & 6.28 & 24.74 & 84.67 \\
\hline Difference Turnout & 1736 & 7.86 & 4.49 & -20.26 & 48.33 \\
\hline Eurosceptic Party Support EP 14' & 1736 & 26.7 & 8.55 & 0.00 & 55.40 \\
\hline Eurosceptic Party Support EP 19’ & 1736 & 24.28 & 7.88 & 0.00 & 53.59 \\
\hline Difference Eurosceptic Party Support & 1736 & -2.42 & 4.49 & -22.09 & 22.85 \\
\hline Electorate & 1736 & 4396 & 15157.55 & 29 & 498570 \\
\hline \multicolumn{6}{|l|}{ Italy } \\
\hline Seconds from cutoff & 3661 & -16314 & 39622.01 & -187047.78 & 1.84 \\
\hline Below cutoff & 3661 & 0.20 & 0.40 & 0 & 1 \\
\hline Funding Received & 3661 & 0.19 & 0.39 & 0 & 1 \\
\hline Turnout EP 14' & 3661 & 59.46 & 15.71 & 13.67 & 93.44 \\
\hline Turnout EP 19' & 3661 & 56.51 & 15.39 & 11.78 & 95.37 \\
\hline Difference Turnout & 3661 & -2.95 & 7.19 & -49.42 & 41.36 \\
\hline Eurosceptic Party Support EP 14' & 3661 & 6.11 & 7.26 & 0.00 & 47.76 \\
\hline Eurosceptic Party Support EP 19’ & 3661 & 34.64 & 12.74 & 3.60 & 69.75 \\
\hline Difference Eurosceptic Party Support & 3661 & 28.53 & 8.52 & -5.42 & 61.91 \\
\hline Electorate & 3661 & 8365 & 41655.01 & 40 & 2301781 \\
\hline
\end{tabular}

Table SI 1: Descriptive Statistics 


\subsection{Additional results}
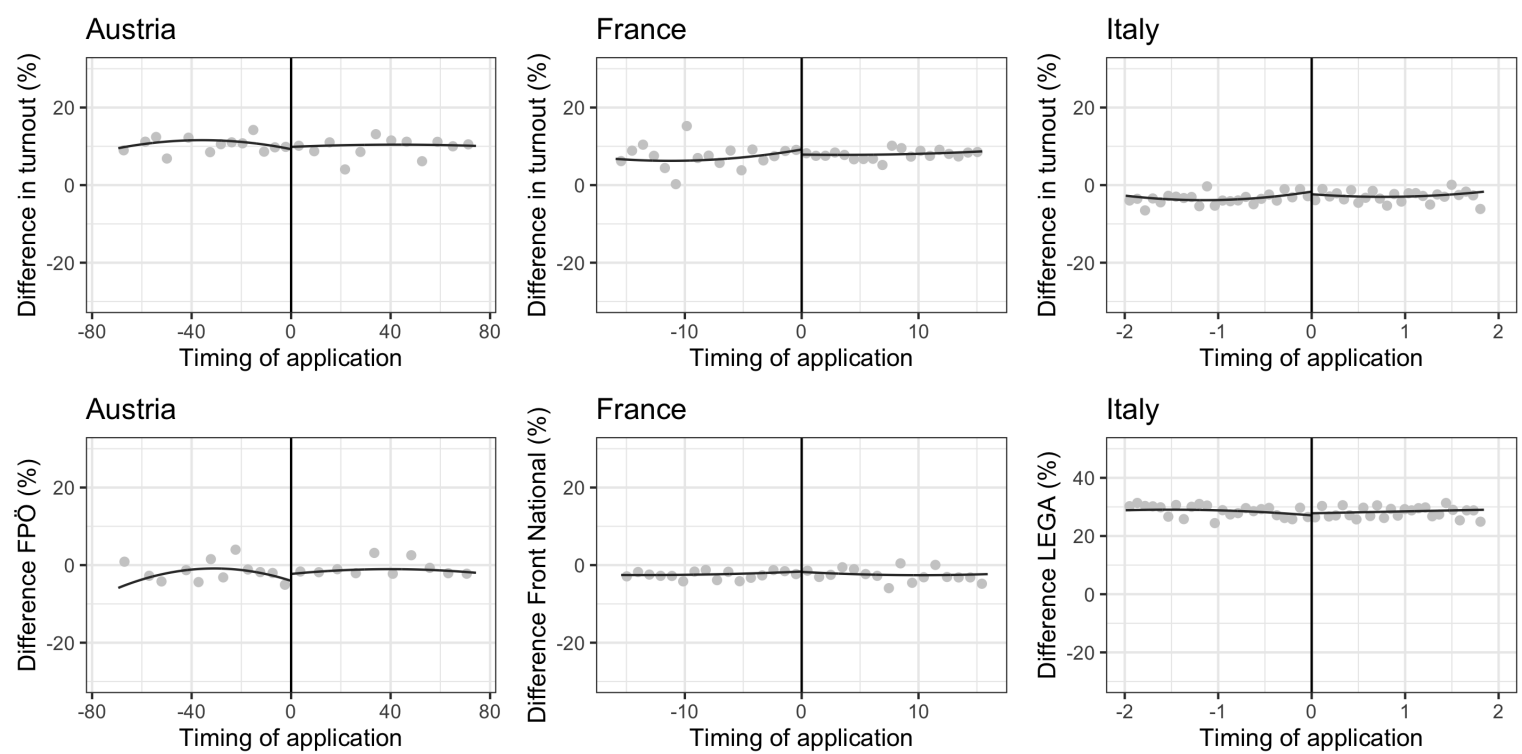

Figure SI 3: Mimicking Variance RD Plot with Evenly-Spaces Bins

Note: Upper panels use differences in turnout as dependent variable. Lower panels use differences in voting results for the main Eurosceptic party as dependent variable. The bandwidth covers the number of seconds (+/-) until the quota was exhausted. Positive values (+) indicate observations before the quota was exhausted and negative values (-) after the quota was exhausted. The global-polynomial of order 2 used to approximate the population conditional mean functions for control and treated units. The triangular kernel function is used to construct the local-polynomial estimator. 

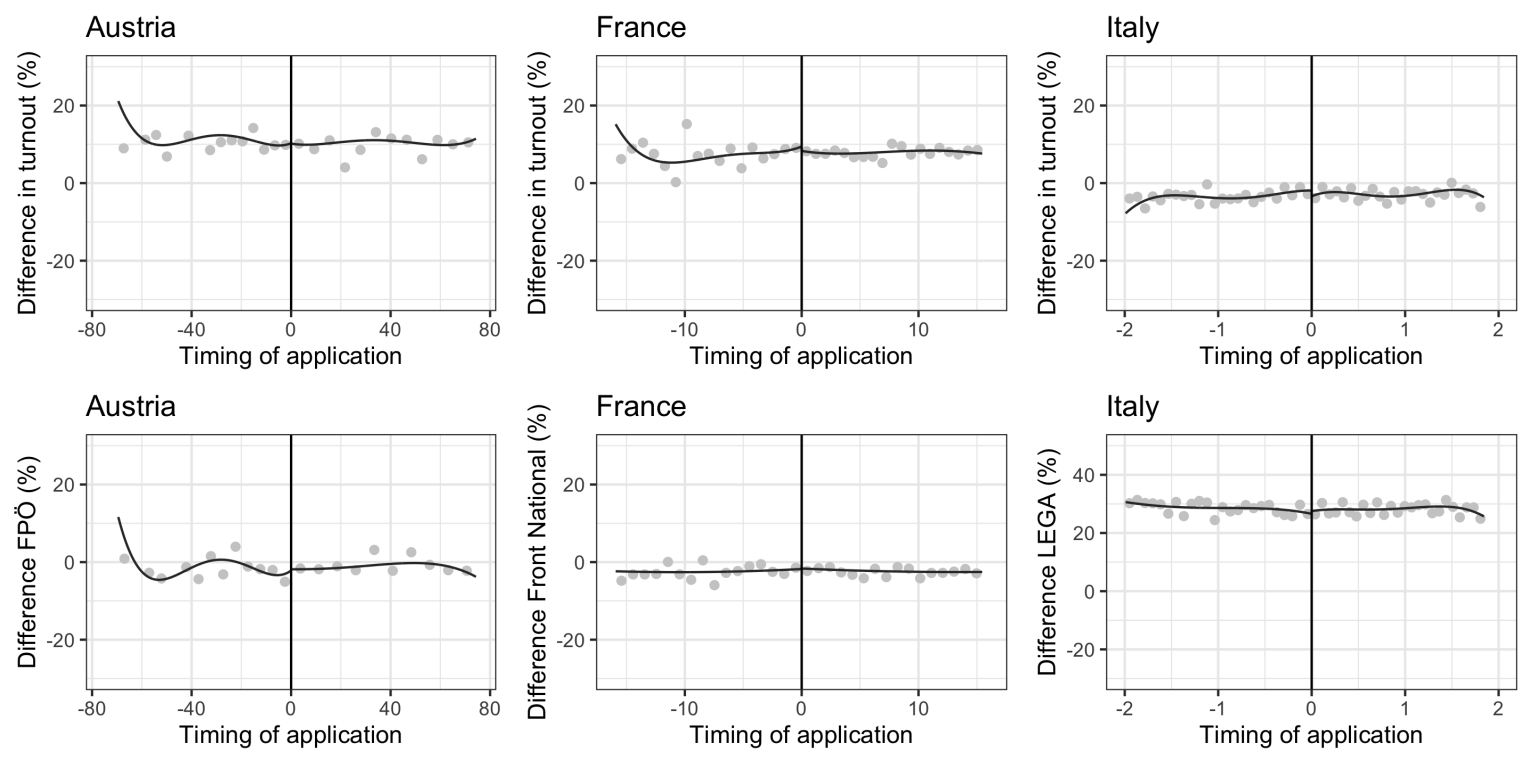

Figure SI 4: Mimicking Variance RD Plot with Evenly-Spaces Bins

Note: Upper panels use differences in turnout as dependent variable. Lower panels use differences in voting results for the main Eurosceptic party as dependent variable. The bandwidth covers the number of seconds (+/-) until the quota was exhausted. Positive values (+) indicate observations before the quota was exhausted and negative values (-) after the quota was exhausted. The global-polynomial of order 4 used to approximate the population conditional mean functions for control and treated units. The triangular kernel function is used to construct the local-polynomial estimator. 


\section{Study 2}

\subsection{Polling station areas}
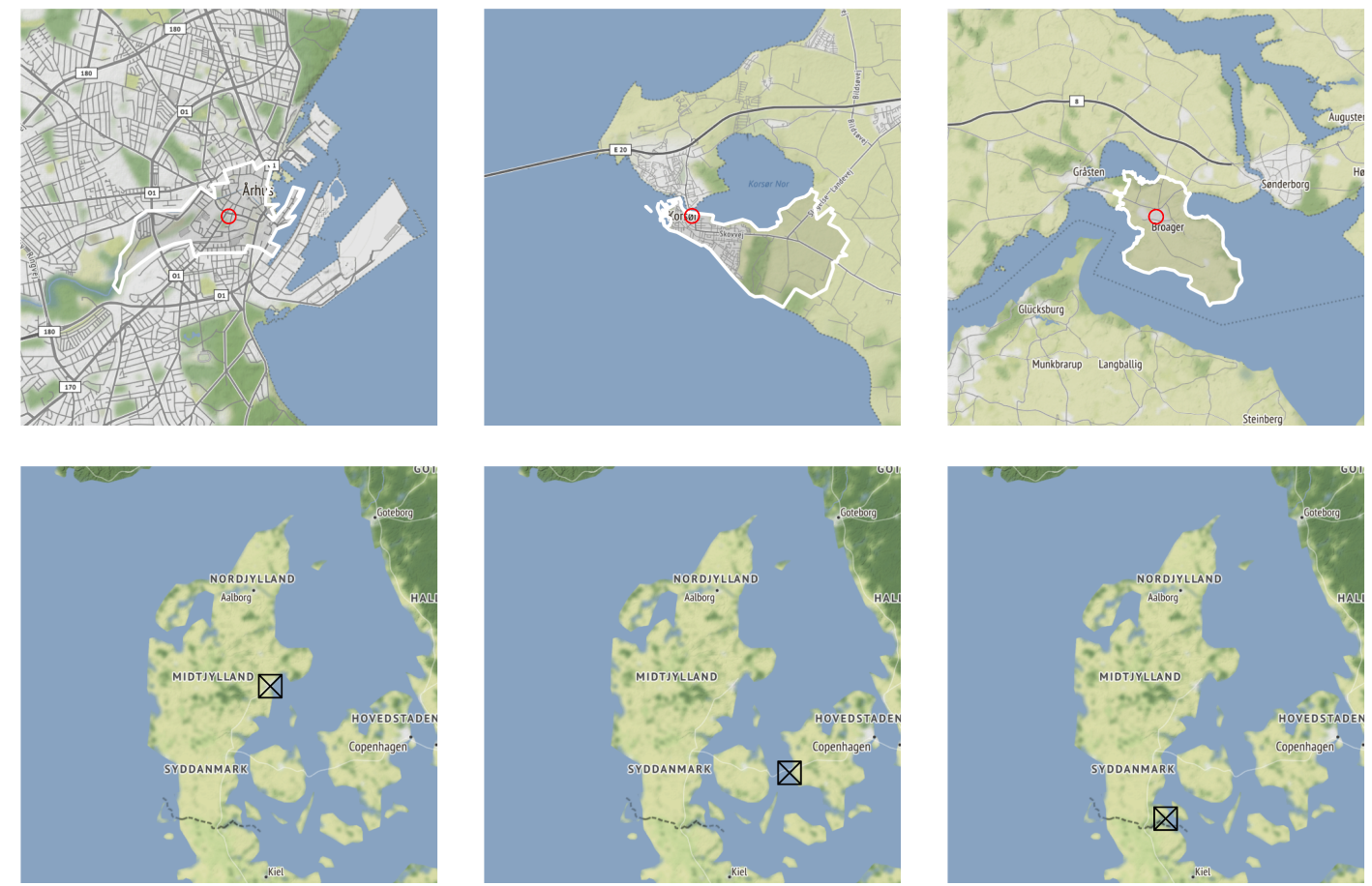

Figure SI 5: Polling station areas

Note: Polling stations (upper panels) and their location on a map of Denmark (lower panel). The red circle in the upper panels shows the location of the polling station.

Left-hand Panel: City hall in Aarhus; Size: $2.50 \mathrm{~km}^{2}$

Center Panel: Storebælts hall in Korsør Søndre Bydel; Size: $13.12 \mathrm{~km}^{2}$ Right Panel: Broager hall in Broager; Size: $39.98 \mathrm{~km}^{2}$ 


\subsection{Descriptive statistics}

\begin{tabular}{lccccc}
\hline \hline Variable & $\mathrm{N}$ & Mean & St. Dev. & Min & Max \\
\hline Turnout EP 09' & 1382 & 60.38 & 6.39 & 37.12 & 80.13 \\
Turnout EP 14' & 1382 & 57.06 & 6.38 & 31.08 & 77.82 \\
Danish People's Party 09' & 1382 & 15.7 & 3.88 & 3.55 & 31.13 \\
Danish People's Party 14' & 1382 & 28.54 & 6.587 & 6.44 & 46.65 \\
project (yes/no) & 1382 & 0.07 & 0.26 & 0 & 1 \\
no. of projects & 1382 & 0.22 & 1.34 & 0 & 31 \\
million DKK & 1382 & 1.53 & 11.90 & 0 & 247.74 \\
\hline no. of households - 09' & 1362 & 1902 & 1918 & 85 & 14860 \\
no. of households - 14' & 1362 & 1836 & 1686 & 85 & 13740 \\
\hline \% households < 100.000 kr. - 09' & 1362 & 2.23 & 1.90 & 0 & 20.71 \\
\% households < 100.000 kr. - 14' & 1362 & 2.23 & 1.94 & 0 & 20.71 \\
\hline 80th percentile annual household income - 09' & 1362 & 813221 & 381288 & 93277 & 3762501 \\
80th percentile annual household income - 14' & 1362 & 795406 & 346441 & 111423 & 3762501 \\
\hline \% migrants - 09' & 1362 & 7.21 & 6.94 & 0.76 & 71.95 \\
\% migrants - 14' & 1362 & 7.21 & 6.98 & 0.76 & 71.95 \\
\hline
\end{tabular}

Table SI 2: Descriptive Statistics 


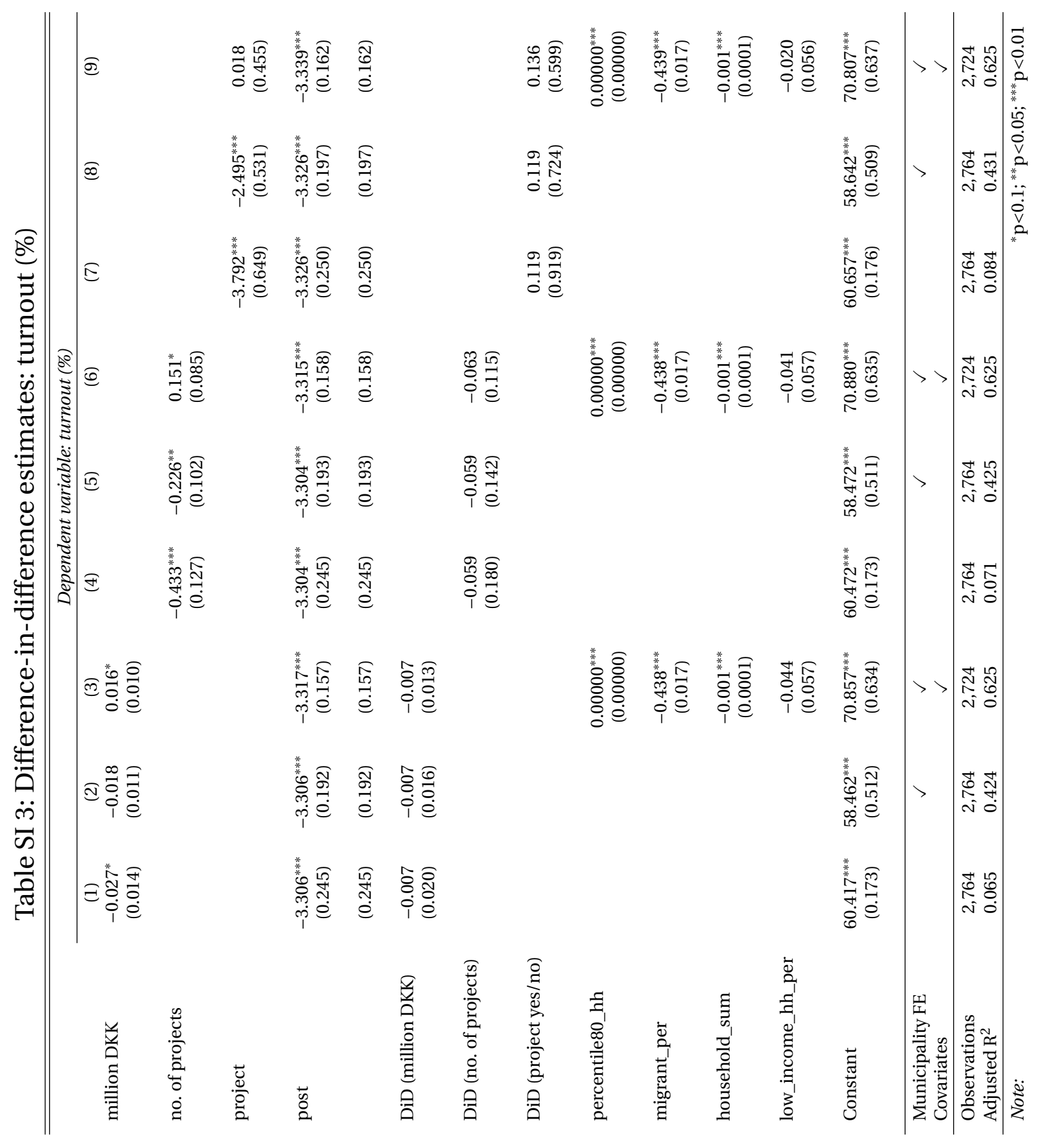




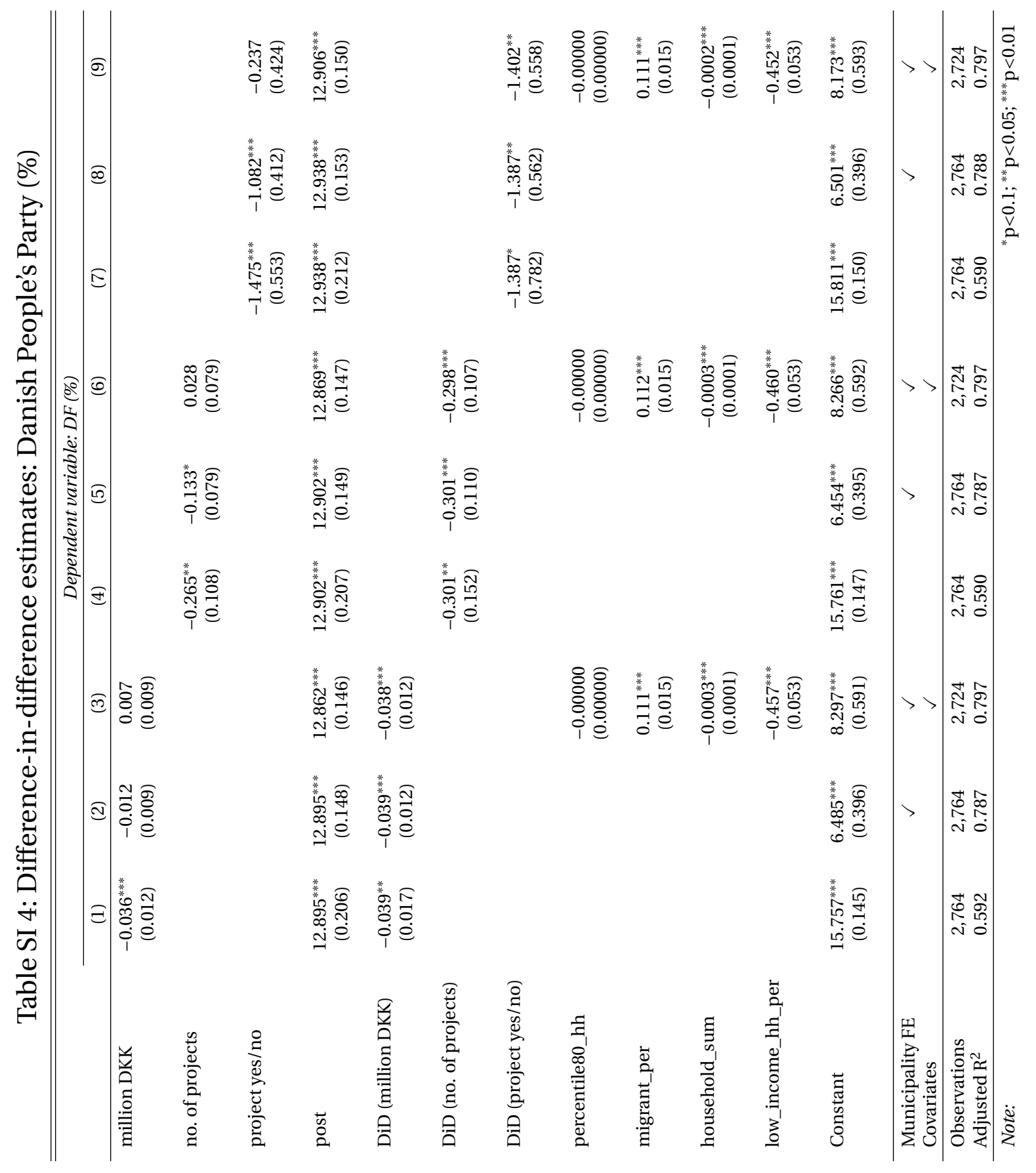




\subsection{Accounting for European funding in neighboring polling sta- tions}

The following tables (Table SI 5 and Table SI 6) present results from spatial-x models in which a spatial variable $\left(W_{x}\right)$ is added to the model equation. The spatial variable $\left(W_{x}\right)$ is the product of a connectivity matrix based on direct contiguity and the corresponding operationalization of European funding. The connectivity matrix is row-standardized and thus captures the average exposure to European funding in the neighboring polling stations. As a result of the row-standardization, the variable EU funding (no/yes) $W_{x}$ is no longer binary because it indicates the average allocation of funding in the neighboring polling station areas. For example, a polling station area with three neighboring polling station areas of which two are home to an EU-funded project and the remaining polling station area is not has a European funding (no/yes) $W_{x}$ value of 0.67

\subsection{Leave-one-out estimation}

A few polling station areas received considerably more European funding both in terms of total amounts and realized projects than the average funded polling station area. I therefore re-estimate models using the share of the Danish People's party as dependent variable by means of leave-on-out estimation. Hence, each model leaves one of the polling station areas out at a time. Results are presented in Figure SI 6 which shows the distribution of point estimates as well as upper and lower confidence intervals by means of density plots. The upper panels show results for the treatment variable indicating whether a project was realized or not. The middle panels show results for the treatment variable indicating the number of projects. The lower panels show results for the treatment variable measuring the total amount of projects in million DKK. All models are based on the third model specification including covariates and municipality fixed effects. Across the 1362 models, most point estimates are very similar to the ones presented in Table 2 . In addition, the estimated $95 \%$ confidence intervals exclude the value of zero across all models. 


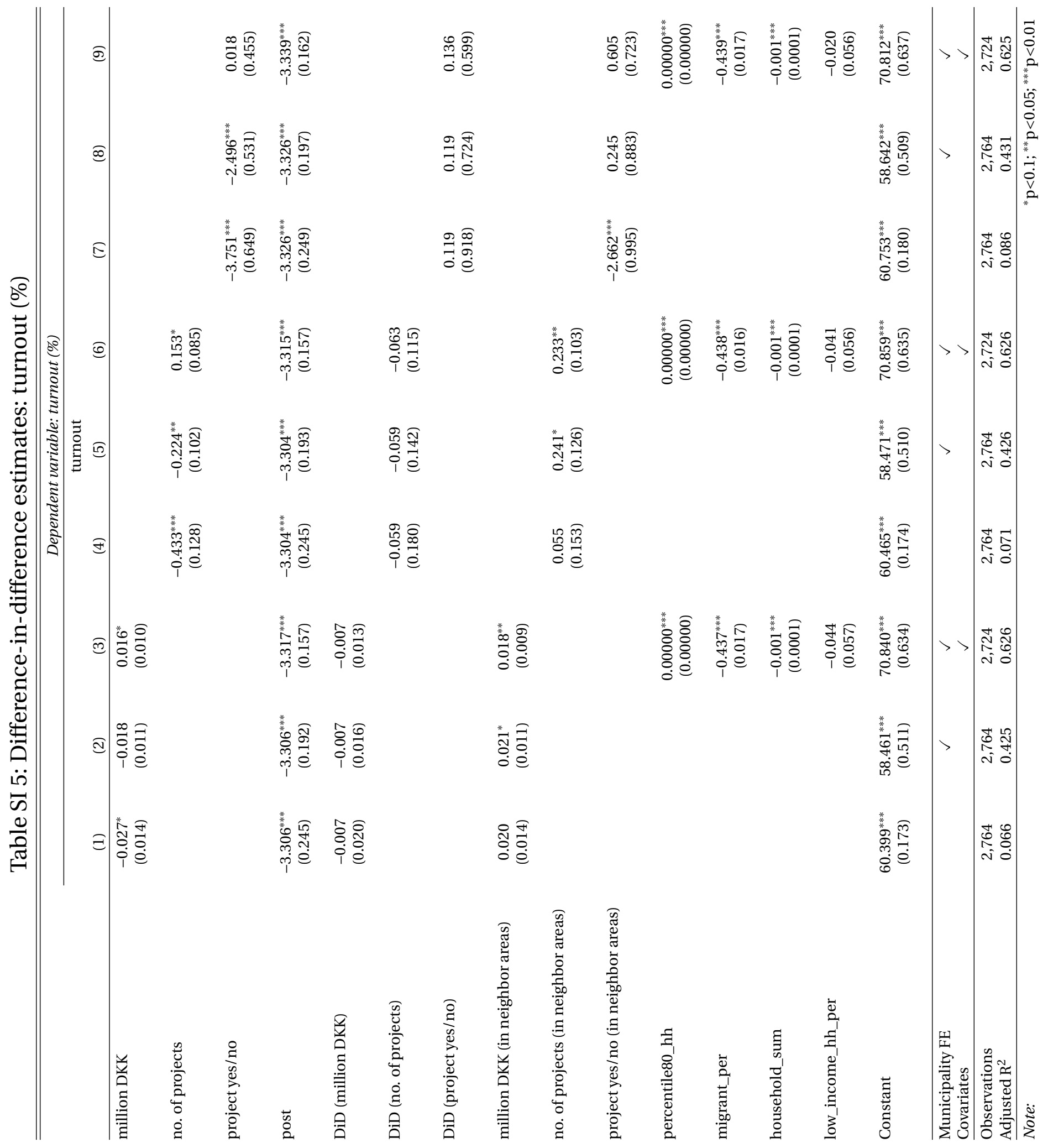




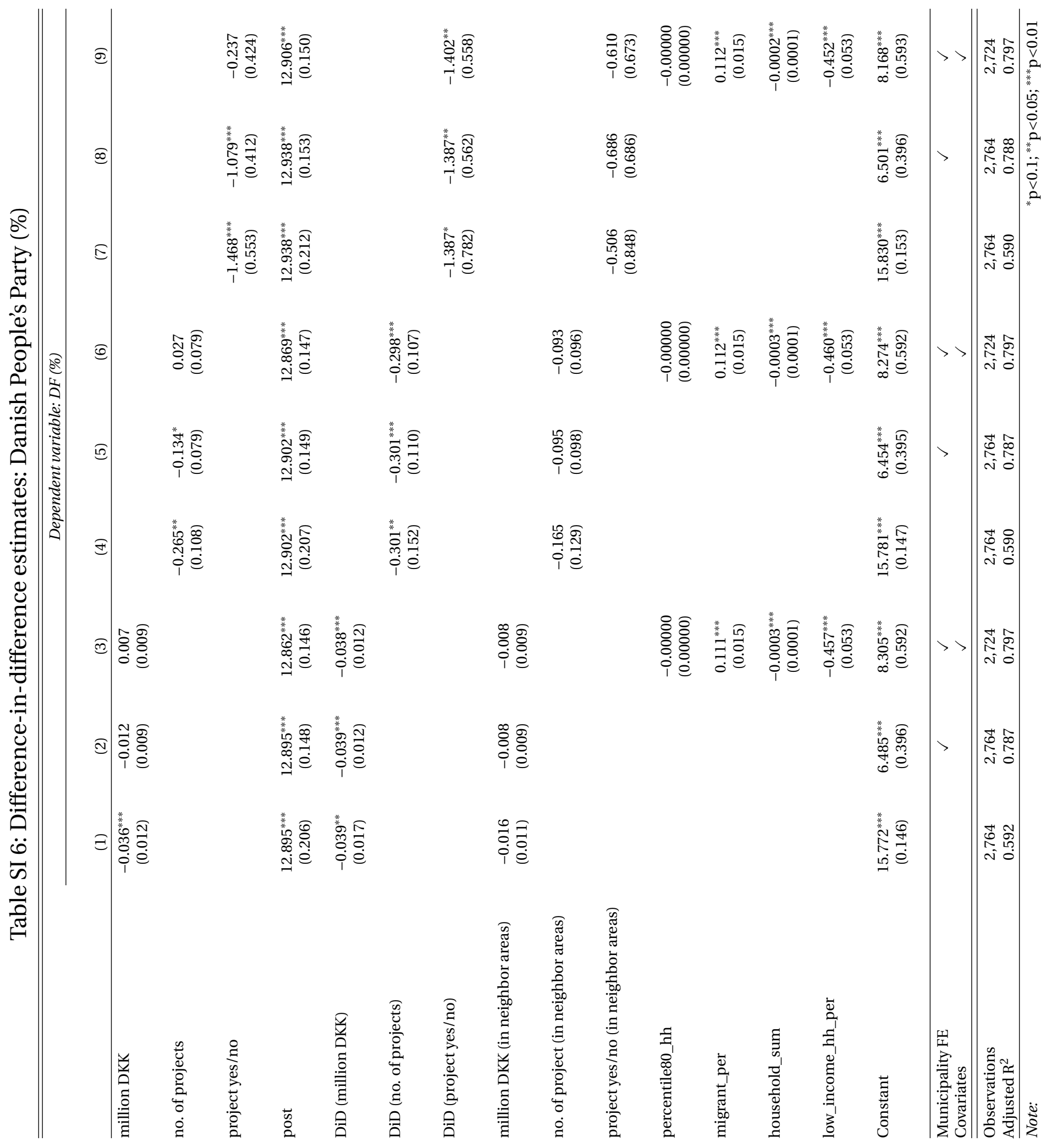


Lower Cl's

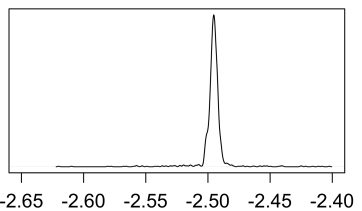

project yes/no

Lower Cl's

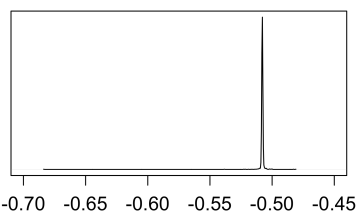

No. of projects

Lower Cl's

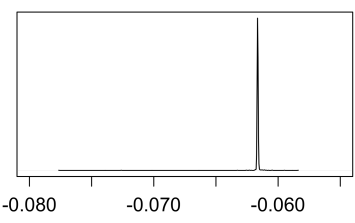

Point estimates

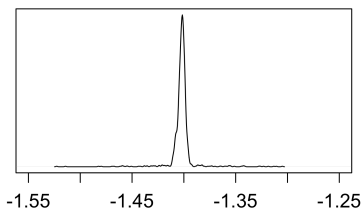

project yes/no

Point estimates

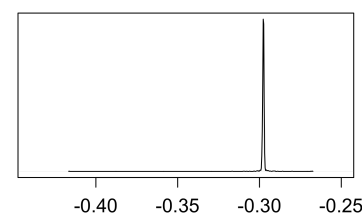

No. of projects

Point estimates

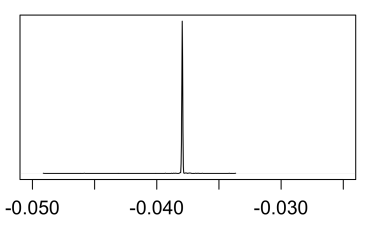

Million DKK
Upper Cl's

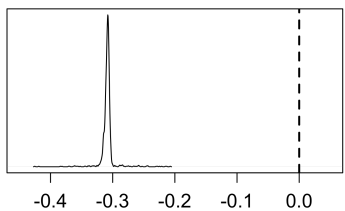

project yes/no

Upper Cl's

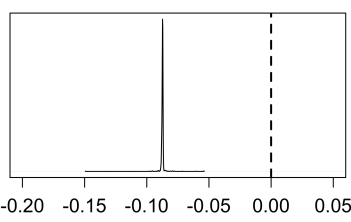

No. of projects

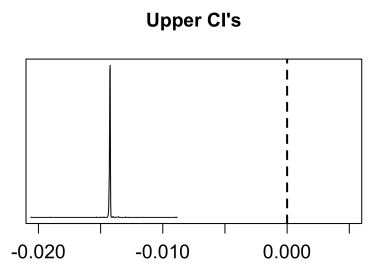

Million DKK

Figure SI 6: 'Leave-one-out' estimation

\section{Study 3}

\subsection{Question wording of the two neutral topics}

\section{Parliamentary EU Committee}

"The Danish Parliament has an EU Committee. The committee examines EU legislation and controls the Danish government's EU decisions. The EU Committee discusses EU legislation and gives a negotiation mandate to the Danish ministers when negotiating on behalf of Denmark in the Council of Ministers in Brussels.

Did you hear or read anything about the EU Committee during the European Parliament election campaign?"

\section{European Commission}

"The Commission plays a key role in the EU. The Commission presents legislative proposals, represents and negotiates for the EU in international contexts. The Commission consists of 28 Commissioners, 1 from each Member State. The current Danish Commissioner is Magrethe Vestager.

Have you heard or read anything about the work of the Danish Commissioner during the European Parliament election campaign?" 


\section{2 (Most) Covariates are balanced across treatment conditions}
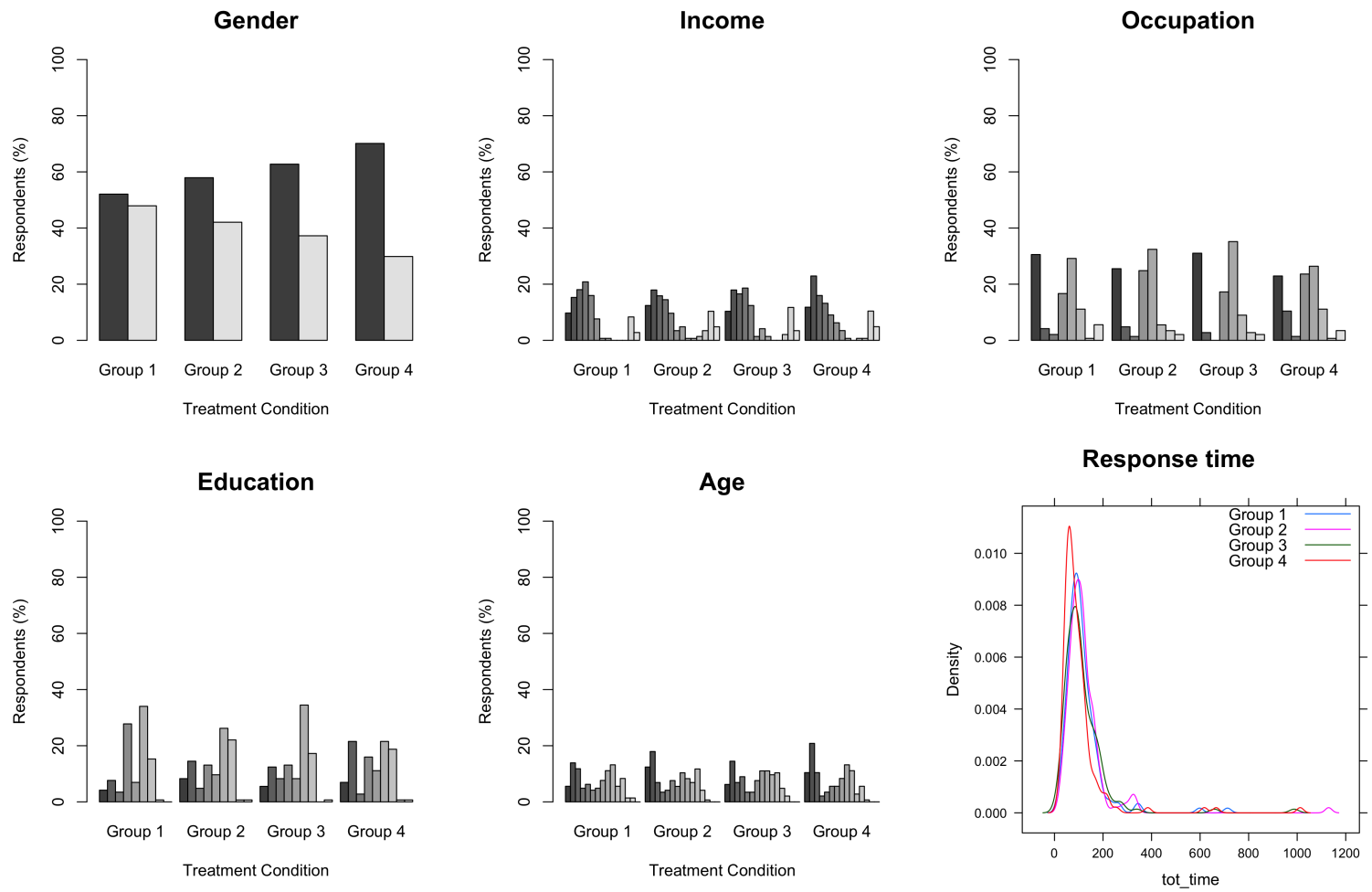

Figure SI 7: Descriptive information on covariates 


\subsubsection{Results controlling for gender}

\begin{tabular}{lcc}
\hline \hline & \multicolumn{2}{c}{ Dependent variable: } \\
\cline { 2 - 3 } & \multicolumn{2}{c}{ Intention to vote } \\
\hline Local & $(1)$ & $(2)$ \\
& 0.033 & 0.034 \\
Regional & $(0.027)$ & $(0.027)$ \\
& & \\
National & -0.002 & -0.001 \\
& $(0.027)$ & $(0.027)$ \\
Gender (male) & 0.012 & 0.014 \\
& $(0.027)$ & $(0.027)$ \\
Constant & & -0.008 \\
& & $(0.020)$ \\
\hline Observations & & $0.894^{* * *}$ \\
\hline \hline Note: Control Group $=$ Reference Category & ${ }^{*} \mathrm{p}<0.1 ;{ }^{* *} \mathrm{p}<0.05 ;{ }^{* * *} \mathrm{p}<0.01$
\end{tabular}

\begin{tabular}{|c|c|c|}
\hline & \multirow{2}{*}{\multicolumn{2}{|c|}{$\begin{array}{c}\text { Dependent variable: } \\
\text { Danish People's Party }\end{array}$}} \\
\hline & & \\
\hline & $(1)$ & (2) \\
\hline Local & $\begin{array}{l}-0.015 \\
(0.033)\end{array}$ & $\begin{array}{l}-0.017 \\
(0.033)\end{array}$ \\
\hline Regional & $\begin{array}{l}-0.031 \\
(0.033)\end{array}$ & $\begin{array}{l}-0.036 \\
(0.033)\end{array}$ \\
\hline National & $\begin{array}{l}-0.015 \\
(0.033)\end{array}$ & $\begin{array}{l}-0.023 \\
(0.033)\end{array}$ \\
\hline Gender (male) & & $\begin{array}{l}0.044^{*} \\
(0.024)\end{array}$ \\
\hline Constant & $\begin{array}{c}0.087^{* * *} \\
(0.023)\end{array}$ & $\begin{array}{c}0.074^{* * *} \\
(0.024) \\
\end{array}$ \\
\hline Observations & 499 & 499 \\
\hline Note: Control Group = Reference Category & ${ }^{*} \mathrm{p}<0.1$ & $05 ;{ }^{* * *} \mathrm{p}<0.01$ \\
\hline
\end{tabular}




\section{The process of allocating European funds}

In what follows, I outline the allocation process for major European Union funds with reference to the funding period 2007-2013. Taken together, there are three stages in the allocation process. At stage one, the budget of the regional policy and the rules for its use are jointly decided by the member states on the basis of a Commission proposal. For the funding period 2007-2013, the Council adopted 'Council Regulation (EC) No 1083/2006 of 11 July 2006 laying down general provisions on the European Regional Development Fund, the European Social Fund and the Cohesion Fund and repealing Regulation (EC) No 1260/1999'. The regulation defines the main objectives, the criteria that must be met to be eligible for funding, the financial resources available, and the criteria for allocating them. Furthermore, principles and rules on partnership, programming, evaluation, management, and monitoring are outlined. Additional regulations adopted by the European Parliament and Council of the European Union, for example specifying the implementation of the regional policy, accompany the above Council regulation.

The three objectives defined for the funding period 2007-2013 are convergence, regional competitiveness and employment, and European territorial cooperation. Convergence aims at helping the less developed regions. It concerns the 84 regions in 17 member states whose per capita GDP is less than $75 \%$ of the EU average. $81 \%$ of the 347 billion euro comprising the regional policy budget for the period 2007-2013 are allocated to regions eligible for the convergence objective. A total of 168 regions in 19 member states are eligible for the objective of regional competitiveness and employment including transition regions and more developed regions. ${ }^{1}$ Finally, funding related to the objective of European territorial cooperation is reserved for transnational cooperation between regions. In sum, the three objectives highlight the EU's policy focus on innovation, the environment, adaptation to social changes, and crossborder cooperation in line with the Lisbon strategy.

At stage two, the Commission works together with the member states to establish agreements on development needs and investment priorities. Member states draft operational programs breaking down objectives into areas for action. These can cover entire countries but also individual regions and can include cooperation programs involving more than one country. The Commission negotiates with the national authorities on the final content of the operational programs. Each program has several priorities, with related targets, depending on the development objectives of the individual member state or region.

At stage three, the programs are then carried out by the member states and their regions. This includes selecting, monitoring and evaluating hundreds of projects. Actors eligible for funding include private and public entities, such as companies, business organizations, NGO's, educational institutions, public authorities, and individuals. The case work is organized by managing authorities in each country and region. Management and delivery of the programs is delegated to administrations at national, regional, and local levels. Member states must guarantee that funds are being spent effectively and in accordance with EU law. They must provide reliable accounting, monitoring and financial reporting systems and identify the responsible

\footnotetext{
${ }^{1}$ Transition regions are defined by having a GDP between $75 \%-90 \%$ of the EU average. More developed regions are defined by having a GDP of more than $90 \%$ of the EU average.
} 
bodies and procedures to ensure an adequate audit trail. An authority must be designated for each operational program that provides the European Commission with an audit strategy including annual audit opinions and control reports. In sum, decisions about European funding at the three stages of the allocation process are made by European and national authorities working in unison, however, the final selection of projects on the ground is ultimately decided by domestic authorities. The close cooperation between European and national authorities reflects the fact that EU-funded projects are co-financed by public or private national actors. 